\title{
Self-Talk as a Regulatory Mechanism: How You Do It Matters
}

\author{
Ethan Kross \\ University of Michigan, Ann Arbor
}

\author{
Emma Bruehlman-Senecal \\ University of California, Berkeley
}

\author{
Jason Moser \\ Michigan State University
}

\author{
Ozlem Ayduk \\ University of California, Berkeley
}

\begin{abstract}
Does the language people use to refer to the self during introspection influence how they think, feel, and behave under social stress? If so, do these effects extend to socially anxious people who are particularly vulnerable to such stress? Seven studies explored these questions (total $N=585$ ). Studies $1 \mathrm{a}$ and $1 \mathrm{~b}$ were proof-of-principle studies. They demonstrated that using non-first-person pronouns and one's own name (rather than first-person pronouns) during introspection enhances self-distancing. Studies 2 and 3 examined the implications of these different types of self-talk for regulating stress surrounding making good first impressions (Study 2) and public speaking (Study 3). Compared with the first-person group, the non-first-person group performed better according to objective raters in both studies. They also displayed less distress (Studies 2 and 3) and engaged in less maladaptive postevent processing (Study 3). Studies 4 and 5 examined how these different forms of self-talk influence the way people appraise social-anxiety-provoking events. They demonstrated that non-first-person language use (compared with first-person language use) leads people to appraise future stressors in more challenging and less threatening terms. Finally, a meta-analysis (Study 6) indicated that none of these findings were moderated by trait social anxiety, highlighting their translational potential. Together, these findings demonstrate that small shifts in the language people use to refer to the self during introspection consequentially influence their ability to regulate their thoughts, feelings, and behavior under social stress, even for vulnerable individuals.
\end{abstract}

Keywords: distancing, stress, social anxiety, rumination, self-regulation, emotion regulation

During the summer of 2010, LeBron James, a future Hall-ofFame basketball player, faced a tough decision. Should he stay with the small market team that nurtured his career from its inception, or move to a larger city market? Shortly after making his choice (he joined the larger market team), he described his decision-making process in an interview noting, "One thing $I$

Ethan Kross, Psychology Department, University of Michigan, Ann Arbor; Emma Bruehlman-Senecal, Psychology Department, University of California, Berkeley; Jiyoung Park, Aleah Burson, Adrienne Dougherty, Holly Shablack, and Ryan Bremner, Psychology Department, University of Michigan, Ann Arbor; Jason Moser, Psychology Department, Michigan State University, East Lansing; Ozlem Ayduk, Psychology Department, University of California, Berkeley.

We thank the many research assistants at Michigan and Berkeley for their assistance conducting the studies, and Vivian Zayas, Robin Edelstein, Phoebe Ellsworth, and Oscar Ybarra for their feedback.

Correspondence concerning this article should be addressed to Ethan Kross, Psychology Department, University of Michigan, Ann Arbor, MI 48109, or to Ozlem Ayduk, Psychology Department, University of California, Berkeley, CA 94720-1650. E-mail: ekross@umich.edu or ayduk@ berkeley.edu didn't want to do was make an emotional decision. I wanted to do what's best for LeBron James and to do what makes LeBron James happy" (Greenberg, 2010).

Notice how James begins by referring to himself using the pronoun $I$, but then quickly switches to using his own name after indicating that he does not want to make an emotional decision. Does this shift from I to James represent a mere quirk of speech? Or could it represent something more-a process, for example, that consequentially influences people's capacity to control their thoughts, feelings, and behavior? Here we suggest that it is the latter. Specifically, we hypothesize that using one's own name and other non-first-person pronouns to refer to the self during introspection is a form of self-distancing that enhances self-regulation. ${ }^{1}$

\section{Harnessing Language to Promote Self-Regulation}

Several lines of research motivate this prediction. First, converging evidence suggests that enhancing psychological distance,

\footnotetext{
${ }^{1}$ People can focus on a variety of stimuli from a psychologically distanced perspective (e.g., the self, other people, other objects; Trope \& Liberman, 2010). We use the term self-distance to refer to instances in which people focus specifically on the self from a distanced perspective.
} 
which we construed broadly as the capacity to transcend one's egocentric viewpoint of a stimulus, facilitates self-regulation. Research in children and adults indicates, for example, that psychological distancing strategies enhance people's capacity to exert self-control when faced with tempting options in the short term (e.g., Fujita, Trope, Liberman, \& Levin-Sagi, 2006; Kober et al., 2010; Mischel \& Rodriguez, 1993; Sigel \& McGillicuddy-De Lisi, 2003). In a similar vein, research on self-reflection indicates that cueing people to reflect on painful past experiences from a selfdistanced or "fly-on-the-wall" visual perspective helps them reflect on their experiences without ruminating (Gruber, Harvey, \& Johnson, 2009; Kross \& Ayduk, 2011; also see Ray, Wilhelm, \& Gross, 2008; Wisco \& Nolen-Hoeksema, 2011).

The concept of self-distancing also factors prominently into several cognitive and behavioral treatment paradigms. Beck (1970) described distancing as a process that allows clients to think objectively about irrational thoughts and emphasized the importance of this process for effective cognitive therapy (pp. 189190) - a view that many scholars have since echoed (e.g., Fresco, Segal, Buis, \& Kennedy, 2007; Ingram \& Hollon, 1986). The concept of distancing, although sometimes referred to as "decentering" or "self as context," is also central to many newer forms of cognitive therapy, which emphasize the importance of enhancing psychological distance from the self for allowing people to observe and accept their feelings (e.g., Hayes, Luoma, Bond, Masuda, \& Lillis, 2006; Teasdale et al., 2002).

These findings are noteworthy in the current context because researchers have speculated that the language people use to refer to the self may influence self-distancing. For example, research on expressive writing conceptualizes the degree of first-person pronouns that people use when writing about emotional experiences as a marker of self-distancing - the fewer first-person pronouns people use, the more people attempt to distance themselves from their experiences (e.g., Cohn, Mehl, \& Pennebaker, 2004; also see Pennebaker \& King, 1999). Supporting this inference, cueing people to reflect on emotional (Grossmann \& Kross, 2010; Kross \& Ayduk, 2008) and nonemotional (Mcisaac \& Eich, 2002) experiences from the visual perspective of a psychologically distanced observer (compared with a first-person visual perspective) leads them to describe these experiences using fewer first-person pronouns.

Why might certain patterns of language use, in particular people's use of non-first-person pronouns and their own name to refer to the self, promote self-distancing? In general, people use these parts of speech when thinking about, referencing, or speaking to other people. Thus, if people use these parts of speech to refer to the self, this may enhance self-distancing by leading people to think about themselves as though they were someone else-albeit another self whose inner thoughts and feelings they have privileged access to. In contrast, people virtually exclusively use first person pronouns when thinking about or referring to the self from their egocentric point of view. Thus, people who use these parts of speech during introspection should think about the self as they normally dofrom a self-immersed, first-person perspective.

In sum, our analysis suggests that the language people use to refer to the self during introspection may influence self-distancing, and thus have consequential implications for their ability to regulate their thoughts, feelings, and behavior under stress. Our first goal was to explore this question.

\section{Exploring Generalizability to Vulnerable Populations: Social Anxiety}

Our second goal was to explore whether social anxiety moderates the self-regulatory benefits of non-first-person language use during introspection. We focused on social anxiety because it can be studied in the laboratory with a high degree of ecological validity. That is, the situations that socially anxious people fear most-being evaluated by others in a social context-can be simulated in the laboratory relatively easily, in ways that lend themselves well to testing predictions about mechanisms underlying self-regulation. Moreover, social anxiety is one of the most common forms of anxiety (e.g., Kessler, Berglund, Demler, Jin, \& Walters, 2005). From the apprehensive partygoer to the anxious public speaker to the socially phobic patient, countless people experience social anxiety and the concomitant negative psychological and physical consequences that it generates.

Cognitive models of social anxiety suggest that socially anxious individuals experience high levels of anxiety in response to the threat of future social interactions (D. M. Clark \& Wells, 1995; Rapee \& Heimberg, 1997). When these situations are possible, they worry excessively about the likelihood of performing poorly, which interferes with their performance. The perception and actuality of their poor performance reinforce their negative beliefs about the self, giving rise to maladaptive postevent processing or rumination (Brozovich \& Heimberg, 2008).

In current cognitive behavioral therapies, social anxiety is treated by challenging negative expectations about upcoming events (e.g., D. M. Clark et al., 2003). However, to the extent that the language people use to refer to the self during introspection influences self-regulation, it might provide an additional (potentially easily implemented) tool for helping vulnerable populations cope with social threat.

\section{Research Overview}

Seven studies examined whether language use during introspection influences people's ability to self-regulate under social stress. Studies $1 \mathrm{a}$ and $1 \mathrm{~b}$ were proof-of-principle studies. They examined whether using non-first-person pronouns and one's own name (non-first-person group from hereon) rather than first-person pronouns (first-person group from hereon) during introspection enhances self-distancing. Studies 2 and 3 then examined the implications of these different forms of self-talk for regulating the cognitive, emotional, and behavioral sequalae of social stress. Studies 4 and 5 examined how these different forms of self-talk influence the way people appraise future stressors. Finally, Study 6 consisted of a meta-analysis that combined data from Studies 2 through 5 to examine whether trait social anxiety moderates the self-regulatory effects of non-first-person language use.

\section{Studies 1a and $1 \mathrm{~b}$}

Our starting point is that using non-first-person pronouns and one's own name to refer to the self during introspection promotes self-distancing. One way to test this prediction is to examine whether language use during self-reflection influences the vantage point that people adopt when visualizing emotional experiences. If non-first-person language use (i.e., "linguistic" self-distancing) 
enhances self-distancing, then people who use this type of language during introspection should be more likely to report seeing themselves in their past experience from an observer's visual perspective (i.e., "visual" self-distancing) than people who use first-person pronouns during introspection. This logic is broadly consistent with construal level theory, which suggests that potentiating psychological distance in one domain enhances psychological distance in other domains (Trope \& Liberman, 2003, 2010).

We tested this prediction by asking participants to analyze their feelings surrounding an anger-provoking (Study 1a) and anxietyprovoking (Study 1b) negative autobiographical experience using first-person pronouns or non-first-person pronouns and their own name. We focused on two types of negative emotional experiences in these studies to examine the reliability and generalizability of our findings. After participants analyzed their feelings, we asked them to indicate the degree to which they adopted the visual perspective of an observer as they reflected on their feelings.

\section{Method}

Participants. In Study 1a, participants were 56 undergraduates $\left(M_{\text {age }}=18.95\right.$ years, $S D_{\text {age }}=4.74 ; 38$ females; $52 \%$ White, 23\% Asian American, 11\% African American, and 14\% other) who received course credit for their participation. In Study 1b, 93 participants were recruited through Amazon Mechanical Turk (MTurk; $M_{\text {age }}=32.23$ years, $S D_{\text {age }}=12.98 ; 50$ females; $79.6 \%$ White, $12.9 \%$ Asian American, 2.2\% African American, and 5.5\% other).

\section{Procedure and materials.}

Baseline affect. After providing informed consent, participants in both studies rated how they felt "right now" $(1=$ very negative, $9=$ very positive; Study 1a: $M=6.35, S D=1.17$; Study 1b: $M=6.74, S D=1.46$ ).

Negative experience recall task. Next, we asked participants to recall for Study 1a an anger-related autobiographical experience:

No matter how well two people get along there are times when they experience conflict ... [T] ake a few moments right now to recall a time when you experienced such conflict with another person-a time when you became truly enraged at this person.

For Study $1 \mathrm{~b}$, we asked participants to recall an anxiety-related autobiographical experience:

No matter how satisfied people are with their lives, there are times when they worry and experience anxiety ... [T] ake a few moments right now to think about a time from your past when you worried about something happening to you.

They were given as much time as they needed to recall their experience (Study 1a: $M_{\mathrm{sec}}=37.18, S D_{\mathrm{sec}}=19.36$; Study 1b: $\left.M_{\mathrm{sec}}=45.16, S D_{\mathrm{sec}}=24.72\right)$. Aside from cueing people to recall different types of experiences, the only other difference between the two sets of recall instructions was that in Study $1 \mathrm{~b}$, we instructed participants to "close their eyes" before the memory recall instructions, whereas participants in Study 1a did not receive this instruction.

Experimental manipulation. Participants were then randomly assigned to reflect on their feelings surrounding their recalled experience using first-person pronouns (Study 1a: $n=28$; Study 1b: $n=49$ ) or non-first-person pronouns and their own name
(Study 1a: $n=28$; Study 1b: $n=44$ ). The instructions used to manipulate linguistic self-distancing were identical in both studies. Participants in the first person group were told:

One of the things we're interested in in this study is the language people use to understand their feelings. Some people try to understand their feelings by thinking about themselves using first-person pronouns, so this is what we would like you to do. Please try to understand why you felt the way you did in the experience you just recalled using the pronouns "I" and "my" as much as possible. In other words, ask yourself, "Why did I feel this way? What were the underlying causes and reasons for my feelings?"

Participants in the non-first-person group were told:

One of the things we're interested in in this study is the language people use to understand their feelings. Some people try to understand their feelings by thinking about themselves using their own name and other non-first-person pronouns, so this is what we would like you to do. Please try to understand why you felt the way you did in the experience you just recalled using the pronoun "you" and "[your own name]" as much as possible. In other words, if your name was Jane, you would ask yourself, "Why did Jane feel this way? What were the underlying causes and reasons for Jane's feelings?"”

Participants had $60 \mathrm{~s}$ to reflect on their feelings following these instructions.

Visual self-distance. Following prior research (Mischowski, Kross, \& Bushman, 2012; Park et al., 2013), participants completed two items to measure visual self-distancing after the reflection period was over. First, participants rated the extent to which they saw the event replay through their own eyes versus watched the event unfold as an observer as they analyzed their feelings ( $1=$ predominantly immersed participant, $7=$ predominantly distanced observer). Second, they rated how far away from the scene they were as they analyzed their feelings $(1=$ very close, saw it through my own eyes; 7 = very far, saw it as if an observer). Ratings on these items were averaged to create a visual selfdistancing index, Study 1a: $\alpha=.74, M=2.72, S D=1.40$; Study $1 \mathrm{~b}: \alpha=.85, M=3.13, S D=1.66$.

Instructional manipulation check. Because we had less control over the online environment in which Study 1b was performed, we administered an instructional manipulation check at the end of the study to ensure that participants paid attention to our instructions. Specifically, participants read, "We are interested in whether you actually take the time to read the directions ... [I]n order to demonstrate that you have read these instructions, please select 'online shopping' and 'check e-mail only' below." Participants were then presented with a series of Internet activity choices with "online shopping" and "check e-mail only" embedded among them.

\section{Results and Discussion}

Preliminary analyses. Twenty-one participants failed the instructional manipulation check: 14 in the first person group and seven in the non-first-person group. They were excluded from subsequent analyses on a priori grounds, leaving 72 participants in Study 1b, 35 in the first person group, and 37 in the non-first-person group.

\footnotetext{
${ }^{2}$ Jane was replaced with Joe for male participants.
} 
This exclusion rate $(23 \%)$ is consistent with prior studies that have used instructional manipulation checks (Oppenheimer, Meyvis, \& Davidenko, 2009). Exclusions did not differ by condition, Study 1a: $\chi^{2}(1)=0.06, p=.80 ;$ Study $1 \mathrm{~b}: \chi^{2}(1)=2.13, p=.15$.

All analyses controlled for baseline affect, which the groups did not differ on, $F_{S}<1$. Gender was not related to the dependent variable in either study, $F_{\mathrm{s}}<1$, and controlling for it did not substantively alter any of the results. Three participants (one in Study 1a; two in Study 1b) had missing values because of omitted responses.

Visual self-distancing. As expected, participants in the nonfirst-person groups displayed significantly higher levels of visual self-distancing than participants in the first-person groups in both Study $1 \mathrm{a}, F(1,52)=5.96, p=.018, \eta_{\mathrm{p}}^{2}=.103$, and Study $1 \mathrm{~b}, F(1$, 67 ) $=4.45, p=.039, \eta_{\mathrm{p}}^{2}=.062$ (see Figure 1). These findings demonstrate that using non-first-person pronouns and one's own name to refer to the self enhances self-distancing.

\section{Studies 2 and 3: Overview}

Having established that using non-first-person language to refer to the self during introspection increases self-distancing, we examined in Studies 2 and 3 whether language use during introspection influences self-regulation under social stress. Both Studies 2 and 3 focused on these same core issues but were designed by different laboratories and implemented independently. As a result, they had similar procedures and focused on a partially overlapping set of dependent variables. Thus, they provide convergent evidence for the role that language use plays in self-regulation across different situations, laboratories, and measures. ${ }^{3}$

\section{Study 2}

We recruited participants for a study on the psychology of first impressions. They were told that they would be asked to make a positive first impression on another person. Prior to engaging in this task, we asked them to reflect on their feelings concerning their upcoming social interaction using either first-person pro-

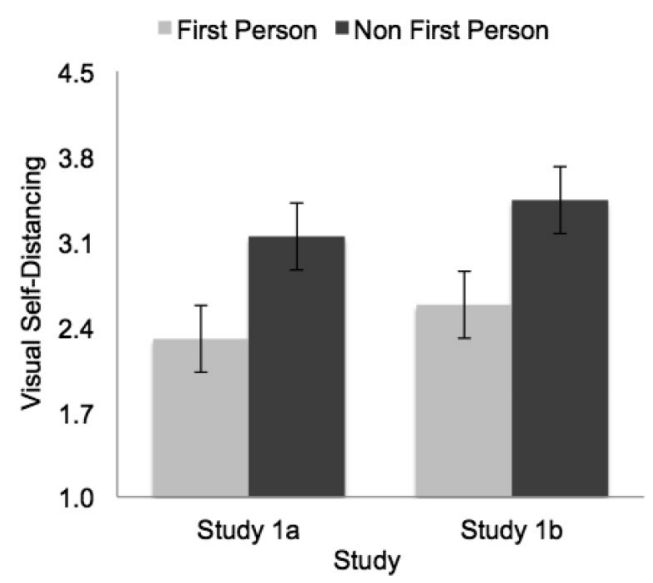

Figure 1. The effect of condition on visual self-distancing in Study 1a and Study $1 \mathrm{~b}$ measured on scales ranging from 1 (predominantly immersed participant) to 7 (predominantly distanced observer). Error bars indicate standard errors. nouns or non-first-person pronouns and their own name. We then examined the effect of this manipulation on participants' anxiety and performance during the social interaction. We predicted that participants in the non-first-person group would experience less anxiety and perform better during the impression formation task

\section{Method}

Participants. Participants were 97 undergraduate women $\left(M_{\text {age }}=20.05\right.$ years, $S D_{\text {age }}=1.86 ; 26.8 \%$ White, $49.5 \%$ Asian American, $5.1 \%$ African American, and $18.6 \%$ other) who received course credit or payment for participating. We focused on women only in this study because they are disproportionately affected by anxiety-related problems, including social anxiety (Kessler et al., 1994; Spurr \& Stopa, 2002; Weinstock, 1999).

Procedure and materials.

Phase 1: Trait social anxiety. Participants completed the 12item Brief Fear of Negative Evaluation Scale (BFNE; Leary, 1983) online approximately 5 days $(M=5.19$ days, $S D=3.41)$ before the study. Sample items include, "I am afraid that others will not approve of me" and "Sometimes I think I am too concerned with what other people think of me" ( $1=$ not at all characteristic of me, $5=$ extremely characteristic of $m e ; \alpha=.80 ; M=37.03, S D=$ 9.23).

Phase 2: Cover story and premanipulation anxiety. Informed consent was obtained at the beginning of the experiment. As part of this process, we informed participants that they would be having a videotaped conversation with another participant. Next, participants rated how anxious they felt $(1=$ not at all, $5=$ extremely; $M=2.30, S D=0.96$ ).

Phase 3: Explanation of study. An experimenter told participants that the study focused on impression formation. Specifically, they were told that their goal would be to make a good first impression during a short conversation with an opposite sex participant after which they would be evaluating each other's performance. In addition, they were informed that their conversation would be videotaped and assessed by trained psychologists who would be rating their social skills. Such "getting to know you" tasks are commonly used to elicit social anxiety in the laboratory (e.g., J. V. Clark \& Arkowitz, 1975; Glass, Merluzzi, Biever, \& Larsen, 1982; Turner, Beidel, \& Larkin, 1986).

Next, the experimenter added that an additional goal of the study was to examine how people can effectively prepare themselves to make good first impressions. Thus, they were told that they would be receiving instructions about how to prepare themselves for their social interaction in a few moments. After these instructions were conveyed, the experimenter left the participant alone in a room without any distractions for $2 \mathrm{~min}$. During this time, the experimenter retrieved the participant's condition assignment from another room.

Phase 4: Experimental manipulation. After the 2-min waiting period, the experimenter told participants, "We are interested in the different ways people go about preparing themselves psychologically for meeting new people and what effect each type of self-preparation has on performance." They were then randomly

\footnotetext{
${ }^{3}$ In Studies 2 and 3, a number of additional measures were included for exploratory purposes. They are available upon request from the corresponding authors.
} 
assigned to a first-person $(n=48)$ or non-first-person $(n=49)$ condition using instructions that were virtually identical to those used in Study 1. The main difference was that participants were asked to think about their feelings concerning an upcoming anxiety-provoking event (rather than a past experience). Following these instructions, participants reflected over their thoughts and feelings alone for $3 \mathrm{~min}$.

Phase 5: Manipulation check and preinteraction anxiety. Following the experimental manipulation, participants answered the following questions, "How well do you feel you followed the speech preparation instructions" $(1=$ not at all well, $5=$ perfectly well) and "To what extent did you use the first-person pronouns $I$ and me (or non-first-person pronouns you and your own name) to refer to yourself when you were working through your thoughts and feelings about the upcoming conversation $(1=$ not at all, $5=$ exclusively). Scores on these questions were averaged to create a manipulation check index $(\alpha=.68 ; M=3.79, S D=0.70)$. Next, participants rated their anxiety again, using the same question that was administered prior to the manipulation $(M=2.84, S D=$ 0.97).

Phase 6: Social evaluation task. Subsequently, the experimenter introduced the participant to a new experimenter and their interaction partner, who was in fact a confederate. Prior research indicates that opposite sex interactions are more anxiety provoking than same sex interactions, especially for socially anxious people (e.g., Turner et al., 1986). Therefore, following prior research (e.g., Burgio, Merluzzi, \& Pryor, 1986; J. Clark \& Arkowitz, 1975; Glass et al., 1982; Kashdan \& Roberts, 2006), the confederate in this study was always male. Both the new experimenter and confederate were blind to condition.

Unstructured interaction. The interaction began when the new experimenter and confederate entered the room and sat across from the participant. The experimenter told the participant that he or she had to leave the room to calibrate the cameras and would return shortly. The participant was given no instructions about how to interact with the confederate during this period. We included this unstructured interaction period to explore whether the manipulation influenced participants' tendencies to spontaneously initiate conversation with their partner. Confederates were instructed not to initiate conversation for the first $30 \mathrm{~s}$. After an initial silence of $30 \mathrm{~s}$, the confederate initiated contact by saying, "It wasn't easy to find the room here today." Three condition-blind raters coded whether participants initiated conversation during the first $30 \mathrm{~s}$ (intraclass correlation [ICC] $=1$ ).

Structured interaction. When the experimenter returned, he or she presented the participant and the confederate with instructions for the social interaction. Following the procedure used by Meleshko and Alden (1993), participants were given a list of topics to talk about (e.g., "What have you always wanted to try but haven't?"; "What is your biggest pet peeve?"). The experimenter instructed them to take turns selecting and answering questions from this list until they had both answered four questions. The confederate always began the exchange and disclosed on the same four questions with all participants. Confederates' responses were scripted so that the content and delivery of their disclosures was consistent. The experimenter left the room prior to the initiation of the conversation and returned after the conversation was over.

Three judges rated participants' performance during this phase on two dimensions. First, they rated how nervous the participant was $(1=$ below average level of nervousness, $5=$ above average level of nervousness; ICC $=.73 ; M=2.87, S D=0.78$ ). Second, they rated participants' overall performance using a modified version of the Social Performance Rating Scale (Fydrich, Chambless, Perry, Buergener, \& Beazley, 1998)—a behavioral assessment of social performance designed for social phobia. Specifically, judges coded participants' behavior along the following four dimensions using a 5 -point scale $(1=$ poor, $5=$ excellent $)$ : gaze, vocal quality, speech length, and discomfort $(\mathrm{ICC}=.73) .{ }^{4}$ Gaze refers to whether the participant made appropriate eye contact with the confederate. Vocal quality refers to whether the participant spoke clearly and varied her vocal tone in an engaging manner. Length refers to whether the participant spoke for an appropriate amount of time when answering the questions (i.e., neither being overly brief nor long-winded) and lacked awkward pauses. Discomfort refers to whether the participant showed verbal (e.g., speech dysfluencies) and nonverbal (e.g., self-manipulative behaviors like hair twirling, facial touching, and so on) indicators of anxiety during the interaction. Following Fydrich et al. (1998), we created a measure of overall performance by summing participants' scores on these dimensions $(\alpha=.80 ; M=13.10, S D=$ 2.05).

Preliminary analyses indicated that scores on the nervousness and overall performance indexes were highly correlated. Therefore, we collapsed them to create a composite behavioral index of social interaction performance after reverse scoring the nervousness scale and then standardizing scores on each measure $(\alpha=$ $.84)$.

Phase 7: Postinteraction anxiety. Participants rated their anxiety at the end of the interaction using the same question they completed earlier $(M=1.81, S D=0.92)$.

Phase 8: Debriefing. Finally, participants were debriefed for suspicion and compensated.

\section{Results}

Preliminary analyses. Four participants in each condition were excluded-four because they suspected that their partner was a confederate and/or inferred the study aims during the funneled debriefing, and four because of protocol errors (e.g., the confederate did not follow protocol)-leaving 89 participants, 44 in the first-person group and 45 in the non-first-person group. Exclusions did not differ by condition, $\chi^{2}(1)=0.00, p=.98$.

The groups did not differ on premanipulation anxiety, $t(86)=$ $0.54, p=.590$, or trait social anxiety, $t(87)=-0.61, p=.541$. Both of these variables were, as expected, related to several of the dependent variables (see Table 1). Therefore, they were included as covariates. Degrees of freedom vary slightly across analyses due to missing data.

Manipulation check. There was no effect of condition on the manipulation check, $F(1,84)=0.00, p=.973, \eta_{\mathrm{p}}^{2}=.000$ (first-person: $M=3.80, S E=0.10$; non-first-person: $M=3.80$, $S E=0.10$ ), indicating that both groups followed the instructions equally well. It should be noted that one-sample $t$ tests indicated that the mean manipulation check score for each group was significantly greater than the midpoint of the manipulation check

\footnotetext{
${ }^{4}$ We did not include the conversational flow category because the structured nature of the interaction did not allow us to code this dimension.
} 
Table 1

Study 2 Zero-Order Correlations Between Measured Variables

\begin{tabular}{lccccrr}
\hline \multicolumn{1}{c}{ Variable } & 1 & 2 & 3 & 4 & \multicolumn{1}{c}{5} & \multicolumn{1}{c}{6} \\
\hline 1. Trait social anxiety & - & $.18^{\dagger}$ & $.23^{*}$ & -.04 & .09 & -.05 \\
2. Premanipulation anxiety (T1) & & - & $.33^{* * *}$ & $.43^{* * * *}$ & -.16 & .08 \\
3. Preinteraction anxiety (T2) & & & - & $.29^{* *}$ & .04 & .04 \\
4. Postinteraction anxiety (T3) & & & & - & .01 & .04 \\
5. Conversation initiation & & & & & - & -.04 \\
6. Performance & & & & & - \\
\hline
\end{tabular}

Note. $\mathrm{T}=$ Time.

${ }^{\dagger} p \leq .10 .{ }^{*} p \leq .05 . \quad{ }^{* *} p \leq .01 .{ }^{* * *} p \leq .005$.

scale: first-person: $t(43)=13.95, p<.001, d=4.25$; and non-first-person: $t(44)=12.14, p<.001, d=3.66$, indicating that both groups also implemented the instructions successfully.

Anxiety. We examined the effect of condition on state anxiety by performing a repeated-measures analysis of covariance (ANCOVA). Time (t) of state anxiety assessment was the within-participant variable (three: premanipulation [t1] vs. preinteraction [t2] vs. postinteraction [t3]), condition was the between-participants variable (two: first-person vs. non-first-person), and trait social anxiety (continuous) was the covariate. This analysis revealed two effects.

First, condition interacted marginally with time, $F(2,84)=$ 2.93, $p=.059, \eta_{\mathrm{p}}^{2}=.065$. To understand the meaning of this interaction, we performed univariate ANCOVAs on the change in anxiety from the (a) first to the second anxiety assessment (preinteraction anxiety [t2] MINUS premanipulation anxiety [t1]), and (b) the second to third anxiety assessment (postinteraction anxiety [t3] MINUS preinteraction anxiety [t2]) with condition as the between-subjects predictor and trait social anxiety as the covariate. These tests demonstrated that condition did not influence change in anxiety from the first to the second anxiety assessment, $F(1$, $85)=0.12, p=.726, \eta_{\mathrm{p}}^{2}=.001$, but did influence change in anxiety from the second to the third anxiety assessment, $F(1$, $86)=4.12, p=.045, \eta_{\mathrm{p}}^{2}=.046$. As Figure 2, Panel A illustrates, the latter result indicated that participants in the non-first-person group displayed a sharper decrease in anxiety after the social interaction than participants in the first-person group. This effect remained significant when performance during the structured phase of the interaction was controlled for, $F(1,83)=4.14, p=$ $.045, \eta_{\mathrm{p}}^{2}=.048$, suggesting that it was not the case that people felt better simply because they performed better.

Second, trait social anxiety interacted with time to predict state anxiety, $F(2,84)=3.48, p=.035, \eta_{\mathrm{p}}^{2}=.077$. To understand the meaning of this interaction, we conducted parallel analyses as described previously. These analyses revealed no relationship between trait social anxiety and change in state anxiety from the first to the second anxiety assessment, $F(1,85)=0.18, p=.670, \eta_{\mathrm{p}}^{2}=$ .002 , but a significant association between trait social anxiety and change in state anxiety from the second to the third anxiety assessment, $F(1,86)=5.65, p=.020, \eta_{\mathrm{p}}^{2}=.062$. The latter result demonstrated that the more apprehensive participants were about social evaluation, the more their anxiety levels declined following the interaction, $p r=-.25, p=.020$, possibly reflecting the relief socially anxious individuals experienced after the interaction was over.

Behavior. We performed logistic regression on initiating contact (yes $=0$ vs. no $=1$ ) with the confederate during the unstructured phase of the social interaction task with condition as the between-subjects predictor and trait social anxiety and premanipulation anxiety as covariates. None of these variables significantly predicted contact initiation, $p \mathrm{~s}>.13$. However, this likely reflects a ceiling effect as $84 \%$ of participants initiated conversation without prompting.
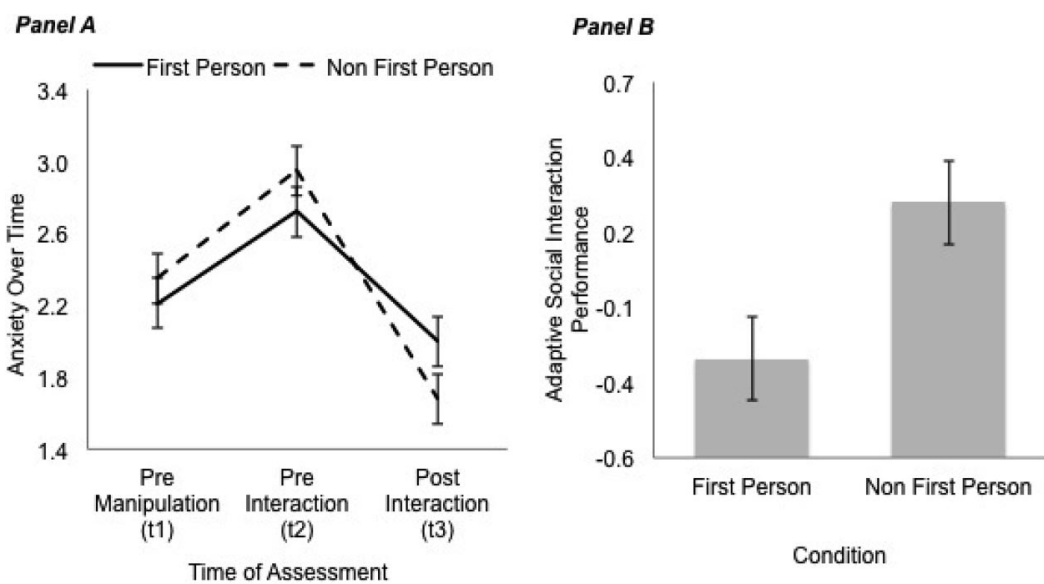

Figure 2. The effect of condition on anxiety over time (Panel A) and adaptive social interaction performance (Panel B) in Study 2. Error bars indicate standard errors. Time $1=\mathrm{t} 1$. 
Next, we performed an ANCOVA on judges' ratings of performance during the structured phase of the interaction with condition as the between-subjects predictor and trait social anxiety and premanipulation anxiety as covariates. Judges' ratings indicated that the non-first-person group performed better on the social interaction task than the first-person group, $F(1,82)=7.18, p=$ $.009, \eta_{\mathrm{p}}^{2}=.081$ (see Figure 2, Panel B). Neither premanipulation anxiety, $F(1,82)=0.51 p=.478, \eta_{\mathrm{p}}^{2}=.006$, nor trait social anxiety, $F(1,82)=0.08, p=.774, \eta_{\mathrm{p}}^{2}=.001$, predicted this variable.

\section{Summary and Discussion}

Study 2 examined whether the language people use to refer to the self during introspection influences how they feel and behave under social stress. It generated three key findings.

First, both groups were equally capable of implementing the self-talk manipulations. This suggests that using non-first-person language during introspection is a feasible alternative to using first-person language.

Second, contrary to our expectations, condition did not influence the increase in anxiety participants reported from the first to the second assessment. However, condition did predict changes in anxiety from the second to the third anxiety assessment, indicating that participants in the non-first-person group (compared with the first-person group) displayed a sharper decrease in anxiety from before to after the social interaction. This finding is particularly noteworthy because it suggests that using non-first-person language to refer to the self during introspection may lead people to recover more quickly from social stressors.

Finally, the experimental manipulation influenced participants' behavior during the social interaction. Judges indicated that participants in the non-first-person group were less nervous during the interaction and performed better than their first-person counterparts. These findings highlight the adaptive behavioral implications that using non-first-person pronouns and one's own name during introspection have for people when they engage in tasks that elicit social stress.

\section{Study 3}

Study 3 examined the implications of the same two types of self-talk that Study 2 focused on for allowing people to regulate their thoughts, feelings, and behavior under social evaluative stress. However, a different social stress induction was used, the focus was on different dependent variables, and men as well as women were included. In so doing, we aimed in Study 3 to extend the Study 2 findings in four ways.

First, in Study 3, we examined whether the Study 2 results would generalize to an arguably more powerful social stress induction-a public speech task rather than an impression formation task (Beazley, Glass, Chambless, \& Arnkoff, 2001; Turner et al., 1986). Building on prior research indicating that visual selfdistancing manipulations generalize to powerful negative affect inductions (Mischowski et al., 2012), we predicted that the benefits associated with using non-first-person pronouns and one's own name during introspection would generalize to this novel context.

Second, although Study 2 included a premanipulation measure of affect that the two groups did not differ on, this measure was administered after participants were informed about the nature of the study. Thus, one could argue that the premanipulation anxiety measure used in Study 2 did not constitute a true baseline measure because anxiety was likely induced to a certain degree among all participants. Study 3 included a true baseline affect measure that was administered before participants learned about the nature of the study.

Third, whereas Study 2 focused specifically on anxiety, Study 3 included measures of both global affect and shame. Shame is the key discrete emotion elicited by public speech tasks (Dickerson \& Kemeny, 2004).

Finally, prior research indicates that people often perseverate over their performance in social-anxiety-provoking tasks, which fuels social anxiety-a process that is often referred to as postevent processing (Brozovich \& Heimberg, 2008; also see NolenHoeksema, Wisco, \& Lyubomirsky, 2008). Therefore, Study 3 included multiple measures of postevent processing to examine whether the experimental manipulations influenced this variable. To the extent that reflecting on the self using non-first-person pronouns and one's own name enhances people's ability to regulate their social anxiety, we predicted that participants who engaged in this process should also display less postevent processing.

\section{Method}

Participants. Participants were 89 undergraduates (60 females; $M_{\text {age }}=19.01$ years, $S D_{\text {age }}=1.04 ; 73.0 \%$ White, $12.4 \%$ Asian American, 6.7\% African American, and 7.9\% other) who received course credit or $\$ 20$ for their participation.

Procedure and materials.

Phase 1: Trait social anxiety. We assessed trait social anxiety using two measures to enhance reliability: the BFNE $(\alpha=.88$; $M=36.02, S D=8.13$ ) and the 17-item Social Phobia Inventory (SPIN; Connor et al., 2000; scale: $0=$ not at all, $4=$ extremely; $\alpha=.88 ; M=21.19, S D=9.91){ }^{5}$ Sample items for the SPIN include, "I am bothered by blushing in front of other people," and "Parties and social events scare me." Both measures were administered approximately 4 days before the experiment $\left(M_{\text {days }}=3.66\right.$, $S D_{\text {days }}=1.76$ ). Scores on the BFNE and SPIN were standardized and collapsed to form a single trait social anxiety index $(\alpha=.69)$.

Phase 2: Baseline affect. After providing informed consent, participants rated how they felt "right now" $(1=$ very negative, 7 = very positive; $M=4.93, S D=1.07$ ).

Phase 3: Stress induction. We induced social stress using a modified version of the Trier Social Stress Task (TSST; Kirschbaum, Pirke, \& Hellhammer, 1993). This task involves having participants deliver a public speech in front of an evaluative audience without receiving sufficient time to prepare; it is one of the most powerful ways of inducing stress in the laboratory among humans (Dickerson, Gruenewald, \& Kemeny, 2004; Dickerson \& Kemeny, 2004). Following established procedures (Kirschbaum et al., 1993), the experimenter told participants that they would have to give a speech on why they are qualified for their "dream" job to a panel of interviewers trained to evaluate speech performance. They were also told that their performance would be videotaped.

\footnotetext{
${ }^{5}$ Due to a protocol error, SPIN Item 17 was not administered. We replaced this missing value with each participant's mean rating of the first 16 items
} 
They were then taken to a small room, which contained a desk and chair, and given $5 \mathrm{~min}$ to prepare. They were not permitted to take notes during this time.

Phase 4: Experimental manipulation. After the 5-min preparation period, participants were told:

Besides preparing the content of a speech, people also need to prepare themselves psychologically before giving a speech, so we are interested in learning about the different ways people go about preparing themselves to give a speech, and what effect each type of selfpreparation has on performance.

They were then randomly assigned to the first-person $(n=45)$ or the non-first-person $(n=44)$ condition using instructions that were virtually identical to those used in Study 2. The key differences were that (a) in this study, participants were directed to analyze their emotions before giving a speech (rather than before engaging in a social interaction task) and (b) "he or she" was given as an example of the type of non-first-person pronoun participants in the non-first-person condition could use in addition to "you.'

Phase 5: Speech task. Next, the experimenter returned and led the participant to another room where they delivered their 5-min speech to two confederates posing as evaluators. A video camera positioned in their field of vision recorded their performance.

Phase 6: Speech performance. Two condition-blind coders watched videotapes of participants' speeches and rated them on three dimensions: confidence, nervousness, and overall performance $(1=$ below average, $5=$ above average $)$. After reverse scoring the nervousness scores, coders' ratings were found to be consistent across these dimensions (Rater 1 : ICC $=.75$; Rater 2 : ICC $=.78$ ). Therefore, we collapsed across all three dimensions to create a single speech performance index for each coder. Judge's ratings on these indexes were collapsed to form a single speech performance index $(\alpha=.86 ; M=3.39, S D=0.83)$.

Phase 7: Postspeech global affect and shame. After participants delivered their speeches, they again rated how they felt "right now" to allow measurement of global affect $(1=$ very negative, $7=$ very positive $, M=4.72, S D=1.16)$. Next, they completed 10 items that compose the Shame and Pride subscales (e.g., "I want to sink into the floor and disappear," "I feel proud"; 1 = not feeling this way at all, 5 = feeling this way very strongly) of the State Shame and Guilt Scale (Marschall, Sanftner, \& Tangney, 1994). We focused on how the manipulation influenced emotions that fall on the shame-pride dimension because they are particularly relevant to public speech challenges (Dickerson et al., 2004). Responses to these items were averaged after reverse scoring the pride ratings, so that higher scores reflected greater shame $(\alpha=$ .90; $M=20.25, S D=7.16$ ).

Phase 8: Postevent processing. Next, the experimenters informed participants that they had to set up the next phase of the study in another room and asked them to sit quietly until they returned in $5 \mathrm{~min}$. This provided participants with an opportunity to ruminate over their speech performance (for a similar approach to assessing rumination, see Ayduk \& Kross, 2008; Gerin, Davidson, Christenfeld, Goyal, \& Schwartz, 2006; Zoccola, Dickerson, $\&$ Zaldivar, 2008). At the end of this 5-min period, postevent processing was assessed in two ways.

First, we asked participants to describe in writing the stream of thoughts that flowed through their mind as they waited for the experimenter to return. Using a 0 (not at all) to 4 (completely) scale, two condition-blind raters coded these essays for recounting and reconstruing. Prior research has linked the tendency to ruminate over negative experiences with higher levels of recounting and lower levels of reconstruing (Ayduk \& Kross, 2010b; Grossmann \& Kross, 2010; Kross, Ayduk, \& Mischel, 2005). Recounting was operationalized as statements in which participants rehearsed the specific chain of events and emotions that they experienced during the speech task (e.g., "I was feeling nervous and fidgeted a lot while I was speaking"). Reconstruing was operationalized as statements in which participants described realizations about their experience during the task (e.g., "I was only given $5 \mathrm{~min}$ to prepare my speech and was thus almost set up to not do well"). Interrater reliability was high for both recounting $(\mathrm{ICC}=.79 ; M=1.13, S D=1.34)$ and reconstruing $(\mathrm{ICC}=.82$ $M=0.49, S D=0.81$ ). Following prior research (e.g., Ayduk \& Kross, 2010b; Kross \& Ayduk, 2008; Kross, Duckworth, Ayduk, Tsukayama, \& Mischel, 2011), we collapsed across both measures by subtracting reconstruing scores from recounting scores to create a single thought content index. Higher scores reflected a greater tendency to recount versus reconstrue $(M=0.63, S D=1.21)$.

Second, after participants wrote their essay, they completed the five-item Rumination Questionnaire (RQ; Mellings \& Alden, 2000), which we modified to apply to a speech task. Specifically, participants rated $(1=$ not at all, $7=$ a lot $)$ five items that assessed the degree to which they brooded over their speech task performance (e.g., "To what extent did you criticize yourself about not handling the speech task well?"; $\alpha=.70 ; M=3.65, S D=1.11$ ).

As expected, these two postevent processing measures were closely related $(\alpha=.71)$. Therefore, we created a single index of maladaptive postevent processing by collapsing the data after standardizing scores on each measure.

Phase 9: Debriefing. Participants were debriefed at the end of the study for suspicion and then compensated. No participant voiced suspicion about the study.

\section{Results}

Preliminary analyses. The groups did not differ on baseline affect, $t(85)=0.26, p=.798$, trait social anxiety, $t(87)=0.70, p=$ .485 , or gender, $\chi^{2}(1)=0.09, p=.764$. As in Study 2, baseline affect and trait social anxiety were included as covariates. Gender was not related to any of the dependent variables, and controlling for it did not substantively alter any of the results (for zero-order correlations, see Table 2). Therefore, it is not discussed further. Degrees of freedom vary across analyses due to missing data.

Affect: Global affect and shame. To facilitate comparisons between global affect and shame, we first reverse scored participants' baseline and postmanipulation global affect scores so that higher numbers on these scales reflected more negative affect, consistent with scores on the Shame scale. We then examined the effect of condition on global affect by performing a repeatedmeasures ANCOVA with time of global affect measurement as the within-participants variable (two: baseline vs. postspeech task), condition as the between-participants variable (two: first-person vs. non-first-person) and trait social anxiety as the covariate. This analysis revealed a significant condition by time interaction, $F(1$, $83)=8.39, p=.005, \eta_{\mathrm{p}}^{2}=.092$, indicating that participants in the first-person group displayed a significant increase in negative affect over time, $F(1,42)=9.80, p=.003, \eta_{p}^{2}=.189$. As Figure 
Table 2

Study 3 Zero-Order Correlations Between Measured Variables

\begin{tabular}{lccccccc}
\hline \multicolumn{1}{c}{ Variable } & 1 & 2 & 3 & 4 & 5 & 6 & 7 \\
\hline 1. Trait social anxiety & - & .12 & .01 & -.07 & .09 & $.26^{*}$ & $.21^{*}$ \\
2. Gender & & - & -.01 & .00 & -.02 & .06 & .06 \\
3. Baseline affect & & & - & -.11 & -.01 & -.09 & .00 \\
4. Performance & & & & - & $.35^{\text {**** }}$ & $-.30^{* * * *}$ & -.07 \\
5. Global affect & & & & - & $.69^{* * * *}$ & $.26^{*}$ \\
6. Shame & & & & & - & $.35^{* * * * *}$ \\
7. Postevent processing & & & & & - \\
\hline
\end{tabular}

Note. To facilitate comparisons between global affect and shame, we reverse scored participants' baseline and postmanipulation global affect scores so that higher numbers on the scales reflected more negative affect. ${ }^{*} p \leq .05 . \quad{ }^{* * *} p \leq .005$.

3, Panel A, illustrates, however, participants in the non-first-person group were buffered against this increase, $F(1,40)=1.20, p=$ $.280, \eta_{\mathrm{p}}^{2}=.029$. The interaction between trait social anxiety and time was not significant, $F(1,84)=0.13, p=.719, \eta_{\mathrm{p}}^{2}=.002$.

We also performed an ANCOVA on shame with condition as the between-subjects predictor, controlling for trait social anxiety and baseline affect. This analysis revealed an effect of condition, $F(1,82)=7.70, p=.007, \eta_{\mathrm{p}}^{2}=.086$. As Figure 3, Panel B, illustrates, non-first-person participants felt less shame after the speech task. Although the effect of baseline affect was not significant, $F(1,82)=0.60, p=.441, \eta_{\mathrm{p}}^{2}=.007$, there was a significant effect of trait social anxiety in the predicted direction, $F(1,82)=$ $5.20, p=.025, \eta_{\mathrm{p}}^{2}=.060$ - trait social anxiety and shame correlated positively, $p r=.24, p=.025$.

Finally, conceptually replicating the Study 2 results, the effect of condition on global affect, $F(1,81)=9.47, p=.003, \eta_{\mathrm{p}}^{2}=.105$, and shame, $F(1,81)=4.91, p=.030, \eta_{p}^{2}=.057$, remained significant when controlling for performance.

Behavior. The effect of condition on speech performance was significant, $F(1,83)=5.43, p=.022, \eta_{\mathrm{p}}^{2}=.061$. As Figure 3, Panel C, illustrates, non-first-person participants performed better during the speech task. The effects of trait social anxiety, $F(1$, $83)=0.21, p=.652, \eta_{\mathrm{p}}^{2}=.002$, and baseline affect, $F(1,83)=$ $1.19, p=.278, \eta_{\mathrm{p}}^{2}=.014$, were not significant.

Postevent processing. The effect of condition on postevent processing was significant, $F(1,83)=5.47, p=.022, \eta_{\mathrm{p}}^{2}=.062$, indicating that non-first-person participants engaged in less postevent processing than first-person participants (see Figure 3, Panel D). The effects of trait social anxiety, $F(1,83)=2.21, p=.141$, $\eta_{\mathrm{p}}^{2}=.026$, and baseline affect, $F(1,83)=0.01, p=.941, \eta_{\mathrm{p}}^{2}=$ .000 , were not significant. The effect of condition on postevent
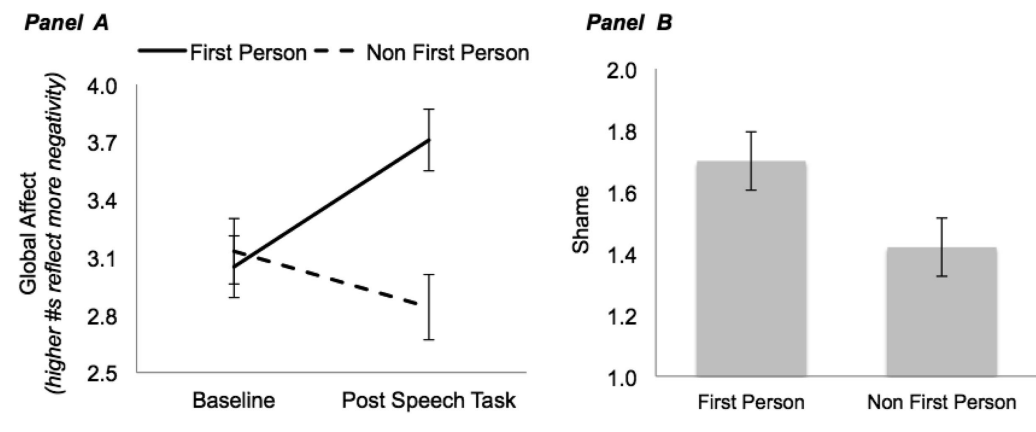

Panel C

\section{Panel D}
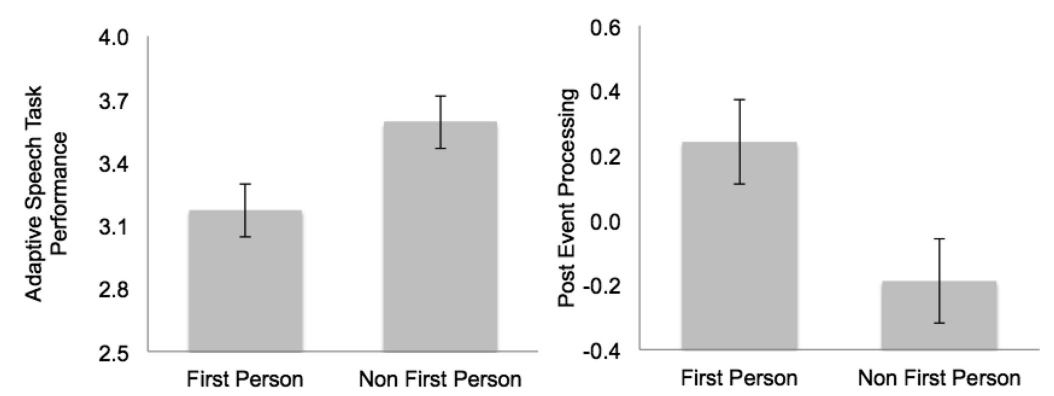

Figure 3. The effect of condition on global affect (Panel A), shame (Panel B), adaptive speech task performance (Panel C), and postevent processing (Panel D) in Study 3. Error bars indicate standard errors. 
processing, $F(1,82)=5.12, p=.026, \eta_{\mathrm{p}}^{2}=.059$, remained significant when controlling for performance.

\section{Summary and Discussion}

In sum, participants who used non-first-person pronouns and their own name during introspection performed better on the speech task, experienced less global negative affect and shame after delivering their speech, and engaged in less postevent processing. These findings extend the Study 2 results in three ways.

First, they demonstrate that non-first-person language use during introspection promotes self-regulation under conditions that are well known to arouse both psychological and physiological stress-an anxiety-provoking public-speaking challenge. Second, they demonstrate that language use during self-reflection has implications not simply for how people think and feel in the moment but also for their tendency to engage in postevent processing. This finding is particularly noteworthy given the role that postevent processing plays as a risk factor for poor psychological (e.g., Nolen-Hoeksema et al., 2008) and physical (Brosschot, Gerin, \& Thayer, 2006) health, and its prevalence in social phobia (e.g., Brozovich \& Heimberg, 2008). Finally, controlling for gender did not alter any of the results we observed. This suggests that the benefits associated with language use as a tool for promoting self-regulation may extend to both genders. Future research that includes larger samples of men is needed, however, to confirm this finding.

\section{Studies 4 and 5 Overview}

The aforementioned studies demonstrate that non-first-person language use during introspection is a form of self-distancing that promotes self-regulation under social stress. However, they do not address how this process influences people's appraisals of future anxiety-provoking events. Studies 4 and 5 addressed this issue.

\section{Study 4}

Study 4 had three goals. Its first goal was to examine how language use during introspection influences people's appraisals of future stressors. In particular, it sought to examine the effect of language use on challenge-threat appraisals.

People naturally appraise future stressors along a challengethreat continuum (Blascovich \& Tomaka, 1996; also see Lazarus \& Folkman, 1984). Challenge appraisals occur when people perceive their ability to cope (i.e., their resources) with a situation as exceeding the demands of the situation; threat appraisals occur when people perceive the demands of the situation as exceeding their ability to cope (e.g., Blascovich \& Tomaka, 1996; Lazarus \& Folkman, 1984).

In the current study, we hypothesized that non-first-person language use would lead people to appraise future stressors in more challenging and less threatening terms. This prediction was motivated by research indicating that visual self-distancing leads people to focus relatively less on the concrete, emotionally arousing aspects of negative past experiences and relatively more on reconstruing their experiences in ways that provide insight and closure (for review, see Ayduk \& Kross, 2010a; Kross, 2009; Kross \& Ayduk, 2011; cf. Fujita et al., 2006; Trope \& Liberman, 2003,
2010). In the current context, we reasoned that focusing on the concrete, emotionally arousing aspects of a future stressful experience are precisely those elements of the situation that should lead a person to conclude that the demands of the situation outweigh his or her ability to cope-i.e., less challenge and more threat. The primary goal of Study 5 was to test this hypothesis.

A secondary goal was to rule out two alternative predictions concerning how language use influences the way people cognitively represent future stressors. First, we examined the relationship between language use during introspection and cognitive avoidance - that is, avoiding cognitions that give rise to anxiety. We focused on this relationship because a number of researchers have speculated that self-distancing blunts emotional reactions via a cognitive avoidance mechanism (e.g., Kenny \& Bryant, 2007; Kenny et al., 2009; Kuyken \& Moulds, 2009).

Another possibility is that non-first-person language use enhances people's tendency to imagine how they appear from the perspective of the audience evaluating them. This prediction is motivated by research indicating that psychological-distancing manipulations can enhance perspective taking (e.g., Eyal \& Epley, 2010; Schultz \& Heimberg, 2008). Although there is conflicting evidence on whether such perspective taking is helpful (e.g., Galinsky, Maddux, Gilin, \& White, 2008) or harmful (e.g., Schultz \& Heimberg, 2008), we nevertheless examined whether non-first-person language use enhances audience perspective taking to examine the role that this process plays in the phenomenon at hand.

The final goal of this study was to examine the reliability of our failure to observe an effect of language use on anticipatory anxiety in Study 2. As noted previously, this null effect was unexpected. Thus, we measured anticipatory anxiety again in this study to examine whether it would replicate.

We examined these issues using a modified version of the speech task paradigm used in Study 3. Specifically, we replicated the Study 3 procedure with the following exceptions. After participants reflected on their feelings, we asked them to rate the extent to which they appraised the upcoming speech task as a challenge or threat, and their current level of anticipatory anxiety. We then asked participants to describe in writing the stream of thoughts that flowed through their mind during the reflection period and coded these essays for challenge-threat appraisals, avoidance, and audience perspective taking.

After participants completed the writing task, they were informed that the study was over and debriefed. We did not have participants deliver their speech because we felt that asking participants to answer each of the aforementioned questions and then describe in writing how they thought about their experience would compromise the downstream effects of the manipulations, muddying the conclusions we could draw about outcomes that were measured subsequently (for similar argument, see Ellsworth \& Gonzalez, 2003; Kassam \& Mendes, 2013; Spencer, Zanna, \& Fong, 2005).

\section{Method}

Participants. Participants were 97 undergraduates (66 females; $M_{\text {age }}=20.39$ years, $S D_{\text {age }}=5.16 ; 51 \%$ White, $35 \%$ Asian American, 8\% African American, and 6\% other) who received course credit or $\$ 20$ for participating in this two-session study. 
Eleven participants did not return for the second session, and five participants declined to participate after learning that they would have to give a speech (but before the manipulations were administered). Thus, data were not available from these participants for analyses.

Procedure and materials.

Phase 1: Trait social anxiety. During a pretest session held approximately 9 days before the experiment $(M=8.56$ days, $S D=5.73)$, participants completed the BFNE $(\alpha=.88 ; M=$ $36.64, S D=8.61)$ and SPIN $(\alpha=.90 ; M=19.46, S D=11.14)$. Scores on these measures were standardized and collapsed to form a trait social anxiety index $(\alpha=.74)$.

Phase 2: Baseline affect. During a laboratory session following the pretest, participants provided informed consent and then rated how they felt "right now" $(1=$ very negative, $7=$ very positive; $M=5.20, S D=1.15)$.

Phase 3: Stress induction. See Study 3.

Phase 4: Experimental manipulation. See Study 3.

Phase 5: Self-report appraisals and anticipatory anxiety. After the reflection period, participants completed a brief survey that contained three questions. We measured threat by asking participants, "How demanding do you expect the upcoming speech task will be?" ( 1 = not very demanding, to $7=$ extremely demanding; $M=3.27, S D=0.92$ ). We measured challenge by asking participants, "How well do you think you will be able to cope with the speech task?" $(1=$ not very well, $5=$ extremely well; $M=3.35, S D=0.84)$. Finally, we measured anticipatory anxiety by asking participants, "How stressed/anxious do you feel about the upcoming speech task?" ( 1 = not very stressed/anxious, $7=$ extremely stressed/anxious; $M=3.40, S D=1.00)$. Following prior research (Blascovich \& Tomaka, 1996; Epel, Daubenmier, Moskowitz, Folkman, \& Blackburn, 2009), we computed a challenge-to-threat ratio by dividing challenge scores by threat scores $(M=1.19, S D=0.77)$ to index appraisals. Higher scores on this measure indicated that participants appraised the speech task more as a challenge (vs. threat).

Phase 6: Stream of thought essays. Next, participants described in writing the stream of thoughts that flowed through their mind during the reflection period. Using a 0 (not at all) to 3 (completely) scale, two raters blind to condition coded these essays on the following dimensions.

Challenge and threat appraisals. We operationalized challenge as statements in which participants indicated that they could cope with the upcoming stressor and/or statements in which participants provided advice or encouragement to themselves to facilitate their performance (e.g., "I feel well experienced for my dream job, and I know that if I can talk about it correctly ..."). We operationalized threat as statements in which participants indicated feeling unprepared or overwhelmed by the demands of task (e.g., "I thought about my stress level and how well I would do in this task. I fear I will be too nervous and not speak well").

Cognitive avoidance. We operationalized avoidance as statements indicating that participants thought about something other than their upcoming speech task (e.g., "I started to think about other things").

Audience perspective taking. We operationalized audience perspective taking as statements indicating that participants put themselves in the shoes of the other people involved in the event they were thinking about to surmise how they would be viewed by them (e.g., "I was focused on saying what I think others would want to hear").

Interrater reliability was good for threat $(\mathrm{ICC}=.89 ; M=1.21$, $S D=1.12)$, challenge $(\mathrm{ICC}=.77 ; M=1.78, S D=1.10)$, cognitive avoidance (ICC $=1.00 ; M=0.02, S D=0.13$ ), and audience perspective taking (ICC $=.69 ; M=0.10, S D=0.33$ ). We divided coded challenge appraisals by coded threat appraisals after adding a constant ("1") to judges' ratings of each essay so that the scores could be divided. Higher scores reflected more challenge compared with threat appraisals $(M=1.81, S D=1.29)$.

The stream-of-thought essay measure was added to the protocol shortly after the study began. Therefore, nine participants were missing data on this measure. In addition, five participants disclosed their condition in their essays. Therefore, data from these participants were not included in the analyses involving essayderived variables; there was no way of doing so without revealing participants' condition information to the coders.

Phase 7: Debriefing. Participants completed a funneled debriefing at the end of the study to assess whether they were aware of the study aims and followed instructions. They were then debriefed and compensated.

\section{Results}

Preliminary analyses. Two participants in the first-person group and four participants in the non-first-person group were excluded on a priori grounds-five indicated that they did not believe they would have to deliver a speech and one indicated that he did not follow the manipulation instructions-leaving 75 participants, 37 in the first person group and 38 in the non-first-person group. Exclusions did not differ by condition, $\chi^{2}(1)=0.65, p=$ .42 .

The groups did not differ on baseline affect, $t(72)=0.82, p=$ .425 , trait social anxiety, $t(73)=-0.11, p=.914$, or gender, $\chi^{2}(1)=0.01, p=.941$. As in Studies 2 and 3, baseline affect and trait social anxiety were included as covariates. Gender was related to self-report challenge-threat appraisals such that women displayed more challenge-threat appraisals than men (see Table 3). However, controlling for this variable did not influence the results. Therefore, it is not discussed further. Degrees of freedom vary slightly across analyses due to missing data.

Challenge versus threat. Condition significantly predicted self-report challenge-threat appraisals, $F(1,70)=7.24, p=.009$, $\eta_{\mathrm{p}}^{2}=.094$. Non-first-person participants appraised the speech task in more challenging and less threatening terms than first-person participants (see Figure 4, Panel A). Baseline affect, $F(1,70)=$ $10.24, p=.002, \eta_{\mathrm{p}}^{2}=.128$, and trait social anxiety, $F(1,70)=$ $7.69, p<.007, \eta_{\mathrm{p}}^{2}=.099$, also predicted this variable-baseline affect was positively related to this variable, $p r=.36, p=.007$, whereas trait social anxiety negatively related to it, $p r=-.32, p=$ .007 .

Condition also predicted coded challenge-threat appraisals, $F(1$, $54)=6.17, p=.016, \eta_{\mathrm{p}}^{2}=.103$-non-first-person participants appraised the task in more challenging and less threatening terms than first-person participants (for examples, see Table 4; also see Figure 4, Panel B). Neither baseline affect, $F(1,54)=0.78, p=$ $.382, \eta_{\mathrm{p}}^{2}=.014$, nor trait social anxiety, $F(1,54)=1.47, p=.231$, $\eta_{\mathrm{p}}^{2}=.026$, predicted this variable. 
Table 3

Study 4 Zero-Order Correlations Between Measured Variables

\begin{tabular}{|c|c|c|c|c|c|c|c|c|}
\hline Variable & 1 & 2 & 3 & 4 & 5 & 6 & 7 & 8 \\
\hline 1. Trait social anxiety & - & .14 & .07 & .20 & $-.26^{*}$ & -.18 & .06 & -.09 \\
\hline 2. Gender & & - & -.12 & .08 & $-.29^{*}$ & -.07 & -.13 & .08 \\
\hline 3. Baseline affect & & & - & -.17 & $.29^{*}$ & .00 & .01 & -.03 \\
\hline 4. Anticipatory anxiety & & & & - & $-.60^{* *}$ & $-.42^{* *}$ & .12 & -.05 \\
\hline 5. Challenge-threat (self-report) & & & & & - & $.43^{* *}$ & -.15 & -.04 \\
\hline 6. Challenge-threat (essay) & & & & & & - & -.27 & -.05 \\
\hline 7. Audience perspective taking & & & & & & & - & -.05 \\
\hline 8. Avoidance & & & & & & & & - \\
\hline
\end{tabular}

Note. Higher scores on baseline affect and global affect reflect lower levels of negative affect. Higher scores on challenge-threat reflect more challenge relative to threat appraisals.

${ }^{*} p \leq .05{ }^{* * *} p \leq .01$

Cognitive avoidance and audience perspective taking. We observed a floor effect on avoidance- $1 \%$ of the essays contained avoidance content. Thus, we did not examine this variable further. Neither condition, $F(1,54)=0.07, p=.795, \eta_{\mathrm{p}}^{2}=.001$, nor trait social anxiety, $F(1,54)=0.07, p=.799, \eta_{\mathrm{p}}^{2}=.000$, nor baseline anxiety, $F(1,54)=0.03, p=.874, \eta_{\mathrm{p}}^{2}=.000$, predicted audience perspective taking.

Anticipatory anxiety. The effect of condition on anticipatory anxiety was significant, $F(1,70)=4.78, p=.032, \eta_{\mathrm{p}}^{2}=.064$. Non-first-person participants $(M=3.19, S E=0.15)$ reported feeling less anxious about their upcoming speech than first-person participants $(M=3.67, S E=0.15)$. We also observed marginally significant effects of trait social anxiety, $F(1,70)=3.43, p=$ $.068, \eta_{\mathrm{p}}^{2}=.047$, and baseline affect, $F(1,70)=3.32, p=.073$, $\eta_{\mathrm{p}}^{2}=.045$. Higher scores on trait social anxiety positively predicted anticipatory anxiety, $p r=.22, p=.068$, whereas baseline affect negatively predicted it, $p r=-.21, p=.073$.

\section{Summary and Discussion}

In Study 4, we examined whether the language people use to reflect on their anxious feelings when preparing to give a public speech alters the way they appraise that event. It generated four key findings.

First, as predicted, participants who reflected on their feelings using non-first-person language appraised their upcoming speech in more challenging and less threatening terms than participants who reflected on their feelings using first-person language. This effect was observed on two types of appraisal measures, highlighting the robustness of these results. These findings are noteworthy because prior research indicates that challenge-threat appraisals influence how people think, feel, and behave under social stress. Specifically, challenge (compared with threat) appraisals predict adaptive subjective, physiological, and behavioral responses (e.g., Blascovich, Seery, Mugridge, Norris, \& Weisbuch, 2004; Dienstbier, 1989; Jamieson, Nock, \& Mendes, 2012).

Second, in contrast to the Study 2 results but consistent with our initial predictions, non-first-person participants displayed less anticipatory anxiety than first-person participants. Thus, it is possible that our failure to observe an effect on anticipatory anxiety in Study 2 was due to chance. Given that we expected and found an effect of condition on this variable in Study 4, we caution against overinterpreting the null results in Study 2.

\section{Panel A}

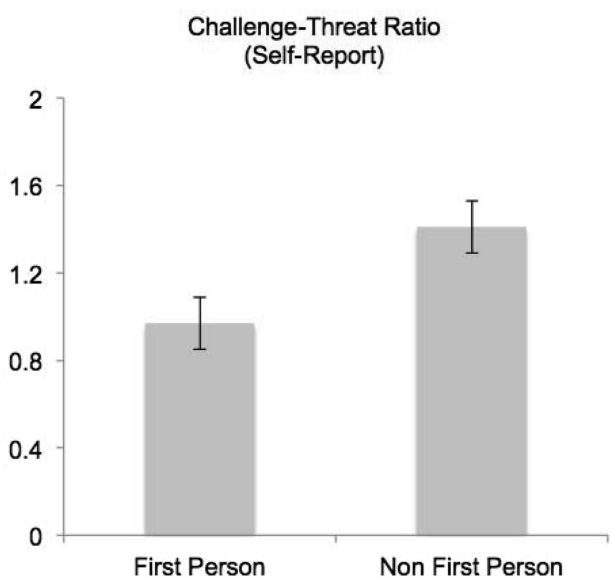

Panel B

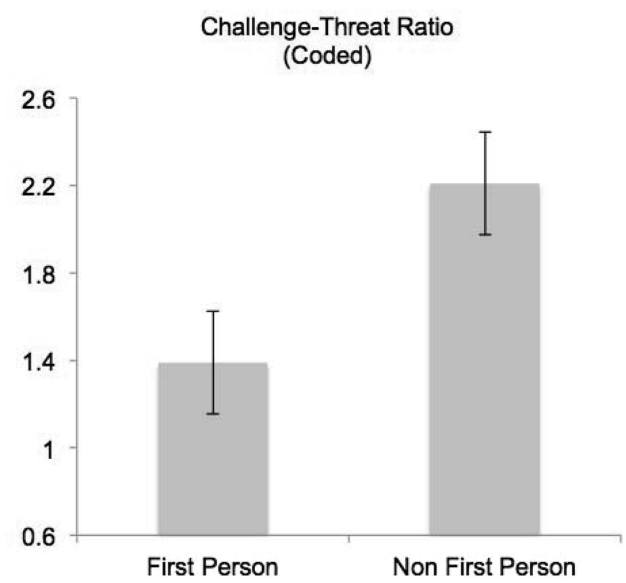

Figure 4. The effect of condition on the ratio of self-reported (Panel A) and coded (Panel B) challenge-threat appraisals in Study 4. Error bars indicate standard errors. 
Table 4

Sample Threat and Challenge Appraisals as a Function of Condition in Study 4

Stream-of-thought essay samples

\begin{abstract}
First-person condition:
I thought that I was so nervous because when I give a speech, I need to feel prepared; however, I don't think I am prepared enough to give a speech such as this one.

I can't prepare an oral speech in 3 min. It takes days for me to examine my strengths, weaknesses, etc. I need to have my oral speech written down and perfected, and therefore, this is not going to work out.

Nervousness. Shock. Not much time to prepare. What did I get myself into? Oh, my goodness. My palms are sweating. What are my weaknesses? Think of really good strengths.

Non-first-person condition:

First, I asked myself what was I nervous about? It's not like this will be the first interview or speech I've ever had to give. And even if it doesn't go perfectly, it won't be the end of the world. I mostly think reassuring and comforting thoughts to motivate and encourage myself.

The topic of my speech, specific wording, the times that I have given a speech like this before. The fact that it's not a "speech" and that word is often associated with a scare tactic and panic inducer.

I told myself that I'm not under a lot of pressure for this. I'm qualified and have worked hard; I have confidence in my abilities.
\end{abstract}

Note. $73 \%$ of participants who received the highest possible score on the challenge-to-threat ratio variable were in the non-first-person group; $67 \%$ of participants who received the lowest possible score on the challenge-to-threat ratio variable were in the first-person group.

Finally, virtually no one avoided focusing on their feelings. This is consistent with research indicating that adopting a visual selfdistanced perspective to analyze one's feelings does not promote cognitive avoidance (Ayduk \& Kross, 2010b; Kross \& Ayduk, 2008, 2009; Kross, Gard, Deldin, Clifton, \& Ayduk, 2012). We also failed to find a significant effect of language use on audience perspective taking, which suggests that using non first person language to reflect on one's feelings does not differentially prime people to think about how they appear in the eyes of others compared to first person language use. These findings, in conjunction with the aforementioned challenge-threat appraisal results, begin to demonstrate how non-first-person language use does and does not influence the way people think about future anxietyprovoking stressors.

\section{Study 5}

The primary goal in Study 5 was to conceptually replicate the effect of language use on challenge-threat appraisals using a larger sample from a different participant pool. We accomplished this goal by recruiting participants using Amazon's Mechanical Turk.

The second goal was to examine the generalizability of the effect of language use on challenge-threat appraisals. Toward this end, we asked participants to reflect on their feelings surrounding any future anxiety-provoking event (not just a speech task).

Our final goal was to refine our understanding on how language use influences challenge-threat appraisals by more directly assessing the relationship between these variables. In Study 4, challenge-threat appraisals were measured by asking participants to self-report how they appraised their upcoming speech task and then retrospectively report on the stream of thoughts that flowed through their mind when they analyzed their feelings. Although both of these are valid measures that are regularly used to interpret how people appraise events, they are both one step removed from the appraisal process itself. That is, they do not directly assess the thoughts and feelings that become activated when people reflect on events. To directly assess such thoughts, we implemented an alternative approach in Study 5 that involved asking participants to work through their current thoughts and feelings surrounding an upcoming anxiety event in writing using first-person or non-first- person language. By having people write about their thoughts and feelings as they experienced them, we hoped to obtain a direct window into how the language manipulations influence the way people appraise upcoming social stressors. ${ }^{6}$

\section{Method}

Participants. Participants were 153 individuals (72 female; $M_{\text {age }}=34.64$ years, $S D_{\text {age }}=12.38 ; 82.4 \%$ White, $7.8 \%$ Asian American, 3.3\% African American, and 6.5\% other) who were recruited via Amazon's Mechanical Turk (Mturk). They were compensated $\$ 0.50$ for their participation.

\section{Procedure and materials.}

Cover story. We obtained informed consent at the beginning of the experiment. Participants were recruited for a study on "writing about emotions from a certain perspective."

Baseline emotion. Participants rated how they felt "right now" using a sliding scale $(0=$ very positive, $100=$ very negative; $M=$ 33.92, $S D=20.50)$.

Trait social anxiety. Next, participants completed the BFNE $(\alpha=.94 ; M=32.65, S D=9.31)$.

Social anxiety reflection task. We then asked participants to think about a current source of social anxiety. They read the following instructions:

No matter how satisfied people are with their lives, there are times that they worry and experience anxiety about things that may go wrong when they interact with other people. Take a few moments right now to think about a specific experience with another person or people that you worry about happening to you from time to time. This could be as minor as worrying about a friend not calling you back or more serious like giving a speech in front of lots of people. As you do this, try to identify a specific experience that makes you feel especially anxious whenever you think about it. Although it may be difficult, most people can usually come up with at least one potential social event that they worry about. Take your time as you try to do this.

\footnotetext{
${ }^{6}$ Additional measures were included for exploratory purposes in this study. They are available upon request from the corresponding authors.
} 
We categorized the type of socially anxious experiences participants reflected on into the following categories: work-related (12\%; e.g., job interview; anxiety-provoking colleague interaction), money-related (3\%; e.g., borrowing money; being homeless), health-related (4\%; worrying about family member's health), performance-related (19\%; e.g., class presentation; exam performance), interpersonal-relationship-related (40\%; e.g., interacting with ex-partner; being excluded from a group), or other (22\%; e.g., impending move).

Experimental manipulations. The experimental manipulation was virtually identical to those in previous studies. The only differences were that participants were asked to write (rather than think) using first-person or non-first-person language to refer to the self.

Appraisals. Two condition-blind judges rated each essay for challenge $(\mathrm{ICC}=.78, M=0.46, S D=0.91)$, threat $(\mathrm{ICC}=.81$, $M=1.78, S D=1.02$ ), avoidance ( $\mathrm{ICC}=.72, M=0.07, S D=$ 0.30 ), and audience perspective taking ( $\mathrm{ICC}=.84, M=0.65$, $S D=0.87$ ) using the same criteria as in Study 4. To preserve judges' blindness to condition, all non-first-person participant essays were converted into first-person essays - that is, names and non-first-person pronouns were replaced with $I$ or $m y$, and the appropriate verb tenses and articles were modified to ensure clarity by a third experimenter who did not code the essays.

Following the procedure used in Study 4, we computed challenge (vs. threat) scores by dividing challenge by threat after adding a constant (" 1 ") to each index $(M=0.73, S D=0.85)$. Higher scores reflected more challenge compared with threat appraisals.

Debriefing. Participants were asked to "describe any other activities that [they] were engaging in while [they] filled out the survey" and then thanked.

\section{Results}

Preliminary analyses. In the current study, participants' essays constituted the manipulation check-that is, by reading participants essays, we were able to determine if they (a) used the type of language they were instructed to use when writing about their anxiety-provoking experience and (b) wrote about a current or future anxiety-provoking experience. Twenty-nine participants failed this check and were thus excluded on a priori grounds-17 wrote about a past (rather than current or future) anxietyprovoking experience, and 12 did not write about an anxietyprovoking experience using the type of language they were asked to use. In addition, seven participants indicated that they were doing something else while they participated (e.g., watched TV, text messaging) and were thus also excluded on a priori grounds. This left 117 participants, 62 in the first-person group and 55 in the non-first-person group. Exclusions did not differ by condition (20 in the first-person and 16 in the non-first-person, $\chi^{2}(1)=0.07, p=$ .79. The overall exclusion rate $(24 \%)$ is consistent with the rate observed in Study 1b, which also used Mturk.

The groups did not differ on baseline affect, $t(115)=1.05, p=$ .295 ; trait social anxiety, $t(115)=0.21, p=.983$; gender, $\chi^{2}(1)=$ $0.63, p=.426$; or type of social anxiety provoking experience, $\chi^{2}(6)=5.39, p=.495 .^{7}$ Controlling for gender and type of social anxiety provoking experience did not substantively alter any of the results we report. Therefore, these variables are not discussed further. As in Studies 2-4, baseline affect and trait social anxiety were included as covariates (for zero order correlations, see Table 5). Degrees of freedom vary across analyses due to missing data.

Challenge versus threat. Conceptually replicating the Study 5 findings, condition predicted challenge (vs. threat) appraisals, $F(1,113)=14.27, p<.001, \eta_{\mathrm{p}}^{2}=.112$-the writing samples of non-first-person participants $(M=1.01, S E=0.11)$ contained more challenge (vs. threat) appraisals than the writing samples of first-person participants $(M=0.44, S E=0.10)$. Table 6 provides examples of the appraisals participants wrote in each condition. They demonstrate that asking people to use their own name and other non-first-person pronouns to refer to the self transformed the way participants thought about their experiences. ${ }^{8}$

Alternative mechanisms: Avoidance and audience perspective taking. Similar to Study 4 , we observed a floor effect on avoidance $-6 \%$ of the essays contained avoidance content. Thus, we did not examine this variable further.

Neither condition, $F(1,113)=0.29, p=.592, \eta_{\mathrm{p}}^{2}=.003$, nor baseline affect, $F(1,113)=0.40, p=.531, \eta_{\mathrm{p}}^{2}=.003$, predicted audience perspective taking. Trait social anxiety did, however, predict this variable, $F(1,113)=5.64, p=.019, \eta_{\mathrm{p}}^{2}=.048-$ higher scores on trait social anxiety predicted more audience perspective taking, $p r=.22, p=.019$.

\section{Summary and Discussion}

These findings conceptually replicate the Study 4 results. They also demonstrate that the effect of language use on challengethreat appraisals generalizes to thinking about a range of socialanxiety-provoking experiences (not only a speech task) and to a nonundergraduate sample.

\section{Study 6}

Although we included trait social anxiety as a covariate in Studies 2-5, we did not examine whether this variable interacted with condition in any of these studies because our statistical power to observe significant interactions in each study was low, considerably lower than our power to detect significant main effects (Frazier, Tix, \& Barron, 2004; Smith, 2000). To overcome this limitation, we performed a meta-analysis in Study 6 on the data from Studies 2-5 (for a similar approach, see Selcuk, Zayas, Gunaydin, Hazan, \& Kross, 2012). Specifically, we examined whether trait social anxiety interacted with condition to predict the following dependent measures, which were assessed in more than one study: anticipatory anxiety (Studies 2-4), postmanipulation affect (Studies 2-3), challenge-threat (Studies 4-5), behavior (Studies 2 and 3), and audience perspective taking (Studies 4 and

\footnotetext{
${ }^{7}$ Because there was overlap between the work- and performance-related categories, we also collapsed across them when performing covariate analyses. Doing so did not influence any results.

${ }^{8}$ After the manipulation, participants were asked to rate how difficult it was for them to implement the instructions. Non-first-person participants reported experiencing marginally more difficulty than first-person participants, $F(1,113)=3.48, p=.07, \eta_{\mathrm{p}}^{2}=.030$. The effect of condition on challenge-threat appraisals remained highly significant when we controlled for this variable, $F(1,112)=12.13, p=.001, \eta_{\mathrm{p}}^{2}=.098$. Thus, the subjective difficulty of the manipulation (or dysfluency) does not account for the effect of language use on appraisals.
} 
Table 5

Study 5 Zero-Order Correlations Between Measured Variables

\begin{tabular}{lcccccc}
\hline \multicolumn{1}{c}{ Variable } & 1 & 2 & 3 & 4 & 5 & 6 \\
\hline 1. Trait social anxiety & - & .04 & $.28^{* * *}$ & -.14 & $.21^{*}$ & -.03 \\
2. Gender & & - & $.16^{\dagger}$ & -.11 & .05 & -.03 \\
3. Baseline affect & & & - & -.03 & .00 & -.02 \\
4. Challenge-threat & & & - & -.04 & -.11 \\
5. Audience perspective taking & & & & - & .12 \\
6. Avoidance & & & & & - \\
\hline
\end{tabular}

Note. Higher scores on baseline affect reflect lower levels of negative affect. Higher scores on challenge-threat reflect more challenge relative to threat appraisals.

${ }^{\dagger} p \leq .10 .{ }^{*} p \leq .05 .{ }^{* * * *} p \leq .005$.

5). We did not examine the moderating role of trait social anxiety on avoidance because we observed a floor effect on this variable in both of the studies that assessed it.

Prior research indicates that vulnerable individuals (i.e., those who score high on individual difference measures of depression or bipolar disorder) benefit as much, or more, from reflecting on emotional experiences from a visual self-distanced perspective as nonvulnerable individuals (Gruber et al., 2009; Kross \& Ayduk, 2009; Kross et al., 2012; Wisco \& Nolen-Hoeksema, 2011). Extrapolating from these findings, we expected people who scored high on trait social anxiety to benefit as much or more from engaging in non-first-person self-talk as people who scored low on trait social anxiety on each of the dependent measures we examined.

\section{Method}

Data analytic strategy. To obtain effect sizes for the interaction between condition and trait social anxiety, we first computed the condition by trait social anxiety interaction term in each study. Next, we computed the correlation between this interaction term and the dependent variable of interest in each study, controlling for baseline affect, condition, and trait social anxiety. We then transformed effect sizes to $z$ scores using Fisher's $r$-to- $z$ transformation. Finally, the transformed effect sizes (i.e., $z$ scores) were weighted by the sample size and averaged across studies (see Table 7). The significance value for this average weighted effect size was computed by dividing it by the standard error. This yielded a Zobt test statistic with a corresponding $p$ value (for similar approach, see Zayas \& Shoda, 2005).

\section{Results and Discussion}

Descriptive statistics. The translational relevance of the results of this study depends largely on whether participants in our samples represent the full spectrum of social anxiety scores. Ideally, one would want to have a sufficient number of individuals who scored low and high on trait social anxiety to draw inferences about the generalizability of this work. Therefore, we first examined whether trait social anxiety scores in each study were normally distributed and covered the range of possible scores on the trait social anxiety scales we administered. As Table 8 demonstrates, both of these criteria were met.

To further address this issue, we examined whether any participants in our samples displayed trait social anxiety scores that resembled those scores displayed by people diagnosed with social phobia. Carleton, Collimore, McCabe, and Antony (2011) suggested that a score of 25 or above on the BFNES (a shortened version of the full BFNE scale that we administered in our studies) reliably distinguishes individuals diagnosed with social anxiety disorder from individuals diagnosed with other Axis 1 disorders. Therefore, we used 25 as a cutoff for determining whether the scores of participants in our studies on this measure resemble those

Table 6

Sample Threat and Challenge Appraisals as a Function of Condition in Study 5

Stream-of-thought essay samples

First-person condition:

I worry about giving a presentation to a customer at work. I am afraid that I will come across as unprofessional or not knowledgeable. I am nervous that they will ask questions that I will not know the answers for. I think I have these feelings because I have had similar experiences in the past where I got nervous because I didn't have an answer.

I am afraid that I won't get a job if I mess up during an interview. And I always mess up in some way. I never know what to say, and I am always incredibly nervous. I end up in a feedback loop of nervousness causing bad interviews causing nervousness. Even if I got a job, I think I would still be afraid of interviews.

A large worry that I have fairly often is regarding public speaking. More specifically, I am in college, so I have many classes that include a number of students. Often times upwards of 300 students. A worry that I get anxious over is that one day the professor will call on me to answer a question or further explain a class concept, and I will freeze up and be unable to respond. I have always had a fear of public speaking; it most likely branches off from my introverted personality. My personality has always been about keeping to myself, and usually staying quiet.

Non-first-person condition:

[Participant's name], you need to slow down. It's a date; everyone gets nervous. Oh jeez, why did you say that? You need to pull it back. Come on man, pull it together. You can do this.

You worry too much about what other people think. You need to focus on what needs to be done, and what you can do to execute it. The simple fact that other people will be around does [not] change what you need to do. Focus on you, and you will be fine.

You can do this, [participant's name]! You can arrange this retirement party for [XXX], and get a good turnout even though he is not well liked. You can come up with a speech. You can get someone else to speak well of him. You can keep the cost of this party within budget. [Participant's name], you can do this! You can get people to pay for the meal and drinks, and you can get them to contribute to a gift. You will make this retirement party a good memory for [XXX].

Note. $75 \%$ of participants who received the highest possible score on the challenge-threat variable were in the non-first-person group; $67 \%$ of participants who received the lowest possible score on the challenge-threat variable were in the first-person group. [Participant's name] and [XXX] are place holders used to protect confidentiality. 
Table 7

Effect Sizes (R) Representing the Associations Between Condition $\times$ Trait Social Anxiety and the Key Dependent Variables Assessed In Studies 2-5

\begin{tabular}{|c|c|c|c|c|c|}
\hline \multirow[b]{2}{*}{ Study } & \multicolumn{5}{|c|}{ Condition $\times$ Trait Social Anxiety } \\
\hline & Challenge-threat & $\begin{array}{l}\text { Perspective } \\
\text { taking }\end{array}$ & $\begin{array}{l}\text { Anticipatory } \\
\text { anxiety }\end{array}$ & $\begin{array}{l}\text { Postmanipulation } \\
\text { affect }\end{array}$ & Behavior \\
\hline 2 & - & - & -.09 & .01 & -.09 \\
\hline 3 & - & - & - & .07 & .04 \\
\hline 4 & -.05 & -.11 & -.11 & - & - \\
\hline 5 & -.12 & .08 & - & - & - \\
\hline Mean weighted $z$ & -.09 & .02 & -.10 & .04 & -.03 \\
\hline
\end{tabular}

Note. Dashes indicate that the measure was not assessed. In Study 3, we collapsed shame and global affect ( $r=$ $.69, p<.001)$ to create a single postmanipulation affect variable. In Study 4, we collapsed self-reported and content-analyzed challenge-threat scores $(r=.43, p<.001)$ to create a single variable. In cases where participants had scores on one challenge-threat measure but not the other, we used the score they had as their value.

scores displayed by people with clinically diagnosed social anxiety. For the SPIN, Connor et al. (2000) noted that individuals diagnosed with social phobia who were judged by a clinician to be moderately ill to very severely ill scored between 33 and 52 .

Table 9 presents the percentage of participants whose trait social anxiety scores were in the range displayed by people who receive clinical diagnoses of social phobia. Overall, $10 \%$ of our sample scored in this range. This percentage is remarkably consistent with the $12 \%$ lifetime prevalence of social phobia in the United States (Kessler et al., 2005), which further suggests that our sample was representative of the larger population in the prevalence of social anxiety and included participants characterized by the full spectrum of social anxiety symptoms. ${ }^{9}$

Meta-analysis. Trait social anxiety did not moderate the effect of language use on anticipatory anxiety, Zobt $=-1.21, p=$ .226; challenge-threat, Zobt $=-1.23, p=.218$; audience perspective taking, Zobt $=0.22, p=.828$; performance under stress, $Z o b t=-0.32, p=.751$; or postperformance affect, Zobt $=0.51$, $p=.610$. Thus, individuals who scored high versus low on trait social anxiety benefited similarly from introspecting using nonfirst-person language. These findings begin to speak to the potential generalizability of language use as a means of helping vulnerable individuals cope with social anxiety.

Table 8

Trait Social Anxiety Score Distribution Statistics

\begin{tabular}{cccccc}
\hline & \multicolumn{2}{c}{$\begin{array}{c}\text { BFNE scale range } \\
(12-60)\end{array}$} & & \multicolumn{2}{c}{ SPIN scale range $(0-68)$} \\
\cline { 2 - 3 } Study & Skew & Score range & & Skew & Score range \\
\hline 2 & -.08 & $17-56$ & & - & - \\
3 & .25 & $19-56$ & & .47 & $3-45$ \\
4 & .58 & $20-59$ & & .83 & $2-47$ \\
5 & .51 & $16-56$ & & - & - \\
\hline
\end{tabular}

Note. Due to a protocol error, 15 people did not complete the Social Phobia Inventory (SPIN) in Study 2. Thus, we did not include it in our analyses. The SPIN was not administered in Study 5. BFNE = Brief Fear of Negative Evaluation Scale (shortened version).

\section{General Discussion}

Immediately after James' infamous interview, Internet message boards were abuzz with people questioning his sanity. Although such reactions are understandable-we are not accustomed to people referring to themselves using their own name-the current findings suggest that doing so promotes self-distancing (Studies 1a and 1b); enhances people's ability to regulate their thoughts, feelings, and behavior under social stress (Studies 2 and 3); and leads them to appraise social-anxiety-provoking events in more challenging and less threatening terms (Studies 4 and 5). They also demonstrate that the self-regulatory effects of this process extend to people regardless of their dispositional vulnerability to social anxiety (Study 6).

\section{Basic Science Implications}

In addition to highlighting the causal implications of language use during introspection for self-regulation, these findings extend research on self-distancing in three ways. First, no previous research has examined how people can self-distance to regulate anxiety surrounding impending social stressors or examined whether individual differences in social anxiety moderate this process. The current findings address these issues directly. They suggest that self-distancing manipulations may be useful in helping people cope not only with depression and anger related to ruminating over the past but also social anxiety surrounding the future.

Second, the current research demonstrates that self-distancing influences people's tendency to appraise upcoming social stressors in more challenging and less threatening terms. In so doing, this work integrates research on self-distancing with a large literature on coping and appraisals.

\footnotetext{
${ }^{9}$ In Study 4, 16 participants did not return for the speech task following the baseline session. The trait social anxiety scores for these participants were marginally higher than the scores for participants who did return, $t=$ $1.77, p=.08$. However, the trait social anxiety scores of only three of these participants met the clinical cutoff for social anxiety.
} 
Table 9

Trait Social Anxiety Score Distributions Within Clinical Range

\begin{tabular}{ccc}
\hline Study & BFNE scores $\geq 25$ & SPIN scores $\geq 33$ \\
\hline 2 & $9 \%$ & - \\
3 & $4 \%$ & $12 \%$ \\
4 & $7 \%$ & $17 \%$ \\
5 & $10 \%$ & - \\
\hline
\end{tabular}

Note. Brief Fear of Negative Evaluation Scale (BFNES) refers to a shortened version of the measure. SPIN $=$ Social Phobia Inventory.

Third, prior research has relied exclusively on visual imagery techniques to examine the role self-distancing plays in self-control. The current findings extend this work by demonstrating that language can be harnessed to promote self-distancing as well. Although these different self-distancing tactics are clearly related (see Studies 1a and 1b), it would be a mistake (in our view) to conceptualize them as equivalent for two reasons. First, although linguistic self-distancing significantly influenced visual selfdistancing in Studies 1a and 1b, it explained only $8 \%$ (on average) of the variance in participants' visual self-distancing scores. If these tactics were identical, then one would have expected the percentage of variance explained to be much higher. Second, it is possible that one self-distancing tactic might work better than another in certain contexts. For example, in circumstances where people have the time and luxury to close their eyes and reflect on a painful past experience, the visual self-distancing tactic might be most useful. However, this tactic may be difficult to implement "online" when people are in the midst of performing a task or interacting with other people. In such situations, linguistic self-talk techniques may be easier to implement. A key challenge for future research is to examine when and why different self-distancing tactics are maximally effective.

Another important issue to address in future work are the causal pathways that underlie the effects of non-first-person self-talk on the different outcomes we assessed in these studies-anticipatory anxiety, challenge-threat appraisals, performance under stress, postperformance affect, and postevent processing. On the one hand, our findings regarding challenge-threat appraisals provide initial clues about the processes that may explain some of the benefits of non-first-person self-talk on self-regulation. Specifically, prior research indicates that experimentally enhancing challenge-threat appraisals enhances performance under stress and reduces post performance distress and perseveration (e.g., Blascovich et al., 2004; Dienstbier, 1989; Jamieson et al., 2012). For example, Jamieson, Mendes, Blackstock, and Schmader (2010) found that cueing people to appraise their anxiety surrounding having to take the Graduate Record Examination (GRE) in challenging terms led them to perform better on the exam, worry less about how anxious they were after the exam, and display healthier patterns of sympathetic nervous system activation. Thus, it is possible that non-first-person self-talk impacted performance under stress and postmanipulation affect and perseveration via its effects on appraisals. Future research is needed, however, to confirm these inferences and rule out alternative causal pathways.

On the other hand, the causal relationships between some of the other variables we assessed in these studies are less clear. The design we employed did not allow us to examine whether antici- patory affect mediates the effect of condition on appraisals, or vice versa, or whether the relationship between these variables is bidirectional. Addressing this question in the future is important for refining our understanding of how self-talk impacts self-regulation and will require designs that continuously or semicontinuously measure affect and appraisals over time to allow for reciprocal and recursive relationships to emerge.

It is also possible - and we suspect likely - that non-first-person language use enhances self-control through additional mechanisms that we did not assess (for a discussion of the importance of recognizing the potential complexity of identifying causal pathways in psychological research, see Bullock, Green, \& Ha, 2010). For example, it may influence people's autonomic reactions to stress and how they strategically deploy their attention before, during, and after stressful tasks. Future research is needed to examine whether these and other theoretically relevant variables play an additional role in explaining how non-first-person language use influences self-regulation.

Another question raised by these findings concerns how they speak to William James's (1890) suggestion that referring to the self using the word me leads people to think about the self as an object of attention (also see Libby \& Eibach, 2011). From our perspective, language use should promote self-distancing when people use parts of speech to refer to the self that they typically use to refer to other people-i.e., second- and third-person pronouns and one's own name. Because $m e$ is virtually always used to refer to the self in daily discourse - it is in fact a first-person pronoun-we do not expect people's use of this pronoun to promote self-distancing. In part, this is due to the fact that $m e$ and $I$ are often used in conjunction with each other to refer to the self. To demonstrate this point, we analyzed participants' essays in Study 5 for the presence of $m e$ using the Linguistic Inquiry Word Count. Note that participants were not explicitly asked to think about themselves using the pronoun me (they were told to use firstperson pronouns and given $I$ as an example). Nevertheless, the effect of condition on $m e$ was significant, $F(1,134)=55.07, p<$ $.001, \eta_{\mathrm{p}}^{2}=.29$, indicating that first-person pronoun participants used me more frequently than non-first-person participants. The use of $I$ and $m e$ was also highly correlated, $r=.57, p<.001$. These findings highlight how tightly interconnected the use of first-person pronouns are in natural discourse, and how likely they are to lead to similar types of mental representations of the self.

\section{Links to Construal Level Theory}

Psychological distance has been the focus of research in numerous areas of psychology over the past half-century. However, within the past decade, construal-level theory (CLT; Trope \& Liberman, 2003, 2010) has emerged as the dominant approach to studying this construct, which raises the following question: How does the concept of self-distance, as discussed throughout this article, compare with the concept of psychological distance as discussed in CLT?

In our view, there is strong conceptual overlap between these concepts. Both are operationalized in terms of allowing people to transcend egocentric viewpoints (e.g., Kross et al., 2012; Trope \& Liberman, 2010), both lead people to generate less concrete and more abstract mental representations (for reviews, see Ayduk \& Kross, 2010a; Kross \& Ayduk, 2011; Trope \& Liberman, 2010), 
and both have been shown to promote self-regulation (e.g., Fujita et al., 2006; Kross \& Ayduk, 2011).

These similarities notwithstanding, whereas people can adopt a psychologically distanced perspective when focusing on virtually any type of stimulus (e.g., the self, another person, another object), the concept of self-distance refers to instances in which people specifically focus on the self from a distanced perspective. Thus, one difference surrounding these concepts and the literatures that use them concerns specificity: whereas research on self-distancing focuses exclusively on self-relevant phenomena, research on psychological distance has a broader focus.

Another point to consider when comparing these constructs concerns the assumption in CLT that four types of psychological distance exist: temporal, spatial, social, and hypothetical (Trope \& Liberman, 2010). Because CLT research has not, to our knowledge, examined self-distance in the way that we manipulate this process, it is not clear whether it represents an additional distancing dimension, or whether it can be captured by one of the aforementioned categories. On the one hand, one could argue that self-distance is a form of "social distance," which maps onto a "self-versus-other" distinction (see Liberman, Trope, \& Stephan, 2007; Trope \& Liberman, 2003). When considering this view, however, it is important to recognize that asking people to think about the self from a distanced perspective is very likely to be psychologically different from reflecting on someone else entirely. In the former situation, a person has privileged access to his or her inner thoughts and feelings. In the latter situation, they do not. Therefore, it is possible that self-distance and social distance represent different dimensions of psychological distance. ${ }^{10}$ Future research is needed to address this issue and is important for integrating research on CLT and self-distance.

\section{Implications for Socially Anxious Individuals}

These findings have multiple implications for research and theory on social anxiety, as well as coping more generally. With respect to social anxiety, they highlight the effect that shifting the language people use to refer to the self under stress has on the cascade of events during and after a social interaction. In this vein, the fact that we observed beneficial effects of non-first-person language use on postevent processing - a cognitive process that has been linked with maladaptive psychological and physical health outcomes in both healthy and clinical populations (e.g., Nolen-Hoeksema et al., 2008) — is particularly noteworthy. It suggests that the current findings may have broad implications for self-control research and practice in multiple populations.

An interesting question for future research concerns whether stable individual differences characterize the spontaneous use of non-first-person language to refer to the self during introspection. The Lebron James interview provides anecdotal evidence suggesting that some people spontaneously think about the self using non-first-person pronouns and their own name under stressful circumstances. Consistent with this anecdote, a recent study by Zell, Warriner, and Albarracin (2012) demonstrated that people are more likely to use second-person pronouns (compared with firstperson pronouns) when thinking about situations that involve self-control than those that do not. Whether the spontaneous use of non-first-person pronouns during self-talk translates into enhanced self-regulation, however, remains unclear, as does whether certain populations of individuals (i.e., healthy vs. clinical) differentially engage in this process.

When considering the broader implications of these findings, it is noteworthy that our manipulation was quite simple-participants were told to use their own name and other non-first-person pronouns when reflecting over their feelings. That such a small shift in the way people reflected on the self led to such consistent results suggests that taking the next steps to examine how these strategies operate in daily life and generalize to clinical populations may be worthwhile.

\section{Self-Distancing and Its Motivational Context}

Finally, it is important to recognize that we studied selfdistancing in a particular context in this study-one in which participants were asked to self-distance and then analyze their feelings. We focused on the joint operation of self-distancing and "asking why" because previous research has consistently shown that self-distancing in the service of fulfilling such epistemic needs leads to beneficial outcomes (Kross \& Ayduk, 2011; also see Wilson \& Gilbert, 2008). However, it is also possible for people to self-distance to achieve other goals. For example, a person could self-distance to observe his or her feelings, an approach that mindfulness and acceptance-based therapies advocate (Bishop et al., 2004; Fresco et al., 2007; Segal, Williams, \& Teasdale, 2002). They could also self-distance to avoid their emotions, a process that many researchers would characterize as harmful (Kenny \& Bryant, 2007; Kenny et al., 2009). These examples suggest that whether self-distancing is helpful or harmful may depend critically on how people focus on the self and their emotions once they engage in this process.

This is especially true for social anxiety because some research indicates that when socially anxious individuals imagine future stressful social interactions, they spontaneously put themselves in the shoes of an evaluative audience, suggesting that self-distancing is harmful for people with social anxiety (e.g., Schultz \& Heimberg, 2008). However, the current research clearly demonstrates that self-distancing, when used to understand one's emotions, is quite distinct from focusing on the self from the perspective of an evaluative audience (i.e., what socially anxious people spontaneously do) and has beneficial downstream consequences for cognition, affect, and behavior. Nevertheless, more research is needed to replicate these effects in both undergraduate and nonundergraduate samples characterized by clinical social anxiety.

\section{Concluding Comment}

Self-talk is a ubiquitous human phenomenon. We all have an internal monologue that we engage in from time to time. The current research demonstrates that small shifts in the language people use to refer to the self as they engage in this process consequentially influences their ability to regulate their thoughts,

\footnotetext{
${ }^{10}$ This is not to say that thinking about the self from a distance bears no similarity to thinking about other people (i.e., social distance). Prior research indicates, for example, that psychological distance diminishes people's reliance on introspective information (e.g., Pronin \& Ross, 2006). That said, individuals still have privileged access to introspective information when they reflect on the self from a distance in a way that they do not when they reflect on another person.
} 
feelings, and behavior under social stress, even for people who are dispositionally vulnerable to social anxiety.

\section{References}

Ayduk, Ö., \& Kross, E. (2008). Enhancing the pace of recovery: Selfdistanced analysis of negative experiences reduces blood pressure reactivity. Psychological Science, 19, 229-231. doi:10.1111/j.1467-9280 .2008.02073.x

Ayduk, Ö., \& Kross, E. (2010a). Analyzing negative experiences without ruminating: The role of self-distancing in enabling adaptive selfreflection. Social and Personality Psychology Compass, 4, 841-854. doi:10.1111/j.1751-9004.2010.00301.x

Ayduk, Ö., \& Kross, E. (2010b). From a distance: Implications of spontaneous self-distancing for adaptive self-reflection. Journal of Personality and Social Psychology, 98, 809-829. doi:10.1037/a0019205

Beazley, M. B., Glass, C. R., Chambless, D. L., \& Arnkoff, D. B. (2001). Cognitive self-statements in social phobia: A comparison across three types of social situations. Cognitive Therapy and Research, 25, 781799. doi:10.1023/A:1012927608525

Beck, A. T. (1970). Cognitive therapy: Nature and relation to behavior therapy. Behavior Therapy, 1, 184-200. doi:10.1016/S00057894(70)80030-2

Bishop, S. R., Lau, M., Shapiro, S., Carlson, L., Anderson, N. D., Carmody, J., . . . Devins, G. (2004). Mindfulness: A proposed operational definition. Clinical Psychology: Science and Practice, 11, 230-241. doi:10.1093/clipsy.bph077

Blascovich, J., Seery, M. D., Mugridge, C. A., Norris, R. K., \& Weisbuch, M. (2004). Predicting athletic performance from cardiovascular indexes of challenge and threat. Journal of Experimental Social Psychology, 40, 683-688. doi:10.1016/j.jesp.2003.10.007

Blascovich, J., \& Tomaka, J. (1996). The biopsychosocial model of arousal regulation. In M. Zanna (Ed.), Advances in experimental social psychology (Vol. 28, pp. 1-51). New York, NY: Academic Press.

Brosschot, J. F., Gerin, W., \& Thayer, J. F. (2006). The perseverative cognition hypothesis: A review of worry, prolonged stress-related physiological activation, and health. Journal of Psychosomatic Research, 60, 113-124. doi:10.1016/j.jpsychores.2005.06.074

Brozovich, F., \& Heimberg, R. G. (2008). An analysis of post-event processing in social anxiety disorder. Clinical Psychology Review, 28, 891-903. doi:10.1016/j.cpr.2008.01.002

Bullock, J. G., Green, D. P., \& Ha, S. E. (2010). Yes, but what's the mechanism? (Don't expect an easy answer). Journal of Personality and Social Psychology, 98, 550-558. doi:10.1037/a0018933

Burgio, K. L., Merluzzi, T. V., \& Pryor, J. B. (1986). Effects of performance expectancy and self-focused attention on social interaction. Journal of Personality and Social Psychology, 50, 1216-1221. doi:10.1037/ 0022-3514.50.6.1216

Carleton, R. N., Collimore, K. C., McCabe, R. E., \& Antony, M. M. (2011). Addressing revisions to the brief fear of negative evaluation scale: Measuring fear of negative evaluation across anxiety and mood disorders. Journal of Anxiety Disorders, 25, 822-828. doi:10.1016/j .janxdis.2011.04.002

Clark, D. M., Ehlers, A., McManus, F., Hackman, A., Fennell, M., Campbell, H., . . . Louis, B. (2003). Cognitive therapy versus fluoxetine in generalized social phobia: A randomized placebo-controlled trial. Journal of Consulting and Clinical Psychology, 71, 1058-1067. doi:10.1037/ 0022-006X.71.6.1058

Clark, D. M., \& Wells, A. (1995). A cognitive model of social phobia. In R. G. Heimberg, M. R. Liebowitz, D. A. Hope, \& F. R. Schneier (Eds.), Social phobia: Diagnosis, assessment, and treatment (pp. 69-93). New York, NY: Guilford Press.

Clark, J. V., \& Arkowitz, H. (1975). Social anxiety and the self-evaluation of interpersonal performance. Psychological Reports, 36, 211-221. doi: 10.2466/pr0.1975.36.1.211
Cohn, M. A., Mehl, M. R., \& Pennebaker, J. W. (2004). Linguistic markers of psychological change surrounding September 11, 2001. Psychological Science, 15, 687-693. doi:10.1111/j.0956-7976.2004.00741.x

Connor, K. M., Davidson, J. R. T., Churchill, L. E., Sherwood, A., Foa, E., \& Weisler, R. H. (2000). Psychometric properties of the Social Phobia Inventory (SPIN): New self-rating scale. British Journal of Psychiatry, 176, 379-386. doi:10.1192/bjp.176.4.379

Dickerson, S. S., Gruenewald, T. L., \& Kemeny, M. E. (2004). When the social self is threatened: Shame, physiology, and health. Journal of Personality, 72, 1191-1216. doi:10.1111/j.1467-6494.2004.00295.x

Dickerson, S. S., \& Kemeny, M. E. (2004). Acute stressors and cortisol responses: A theoretical integration and synthesis of laboratory research. Psychological Bulletin, 130, 355-391. doi:10.1037/0033-2909.130.3 .355

Dienstbier, R. A. (1989). Arousal and physiological toughness: Implications for mental and physical health. Psychological Review, 96, 84-100. doi:10.1037/0033-295X.96.1.84

Ellsworth, P. C., \& Gonzalez, R. (2003). Questions and comparisons: Methods of research in social psychology. In M. A. Hogg \& J. Cooper (Eds.), The Sage handbook of social psychology (pp. 24-42). London, England: Sage.

Epel, E., Daubenmier, J., Moskowitz, J. T., Folkman, S., \& Blackburn, E. (2009). Can meditation slow rate of cellular aging? Cognitive stress, mindfulness, and telomeres. Annals of New York Academy of Sciences, 1172, 34-53. doi:10.1111/j.1749-6632.2009.04414.x

Eyal, T., \& Epley, N. (2010). How to seem telepathic: Enabling mind reading by matching self-construal. Psychological Science, 21, 700705. doi:10.1177/0956797610367754

Frazier, P. A., Tix, A. P., \& Barron, K. E. (2004). Testing moderator and mediator effects in counseling psychology research. Journal of Counseling Psychology, 51, 115-134. doi:10.1037/0022-0167.51.1.115

Fresco, D. M., Segal, Z. V., Buis, T., \& Kennedy, S. (2007). Relationship of posttreatment decentering and cognitive reactivity to relapse in major depression. Journal of Consulting and Clinical Psychology, 75, 447455. doi:10.1037/0022-006X.75.3.447

Fujita, K., Trope, Y., Liberman, N., \& Levin-Sagi, M. (2006). Construal levels and self-control. Journal of Personality and Social Psychology, 90, 351-367. doi:10.1037/0022-3514.90.3.351

Fydrich, T., Chambless, D. L., Perry, K. J., Buergener, F., \& Beazley, M. B. (1998). Behavioral assessment of social performance: A rating system for social phobia. Behaviour Research and Therapy, 36, 9951010. doi:10.1016/S0005-7967(98)00069-2

Galinsky, A. D., Maddux, W. W., Gilin, D., \& White, J. B. (2008). Why it pays to get inside the head of your opponent: The differential effects of perspective taking and empathy in negotiations. Psychological Science, 19, 378-384

Gerin, W., Davidson, K. W., Christenfeld, N. J. S., Goyal, T., \& Schwartz, J. E. (2006). The role of angry rumination and distraction in blood pressure recovery from emotional arousal. Psychosomatic Medicine, 68 64-72. doi:10.1097/01.psy.0000195747.12404.aa

Glass, C. R., Merluzzi, T. V., Biever, J. I., \& Larsen, K. H. (1982). Cognitive assessment of social anxiety: Development and validation of a self-statement questionnaire. Cognitive Therapy and Research, 6, 37-55. doi:10.1007/BF01185725

Greenberg, J. (2010). Exiting via the low road. Retrieved from http://sports espn.go.com/chicago/nba/columns/story? $\mathrm{id}=5365985$

Grossmann, I., \& Kross, E. (2010). The impact of culture on adaptive versus maladaptive self-reflection. Psychological Science, 21, 11501157. doi: $10.1177 / 0956797610376655$

Gruber, J. Harvey, A. G., \& Johnson, S. L. (2009). Reflective and ruminative processing of positive emotional memories in bipolar disorder and healthy controls. Behaviour Research and Therapy, 47, 697-704. doi 10.1016/j.brat.2009.05.005 
Hayes, S. C., Luoma, J. B., Bond, F. W., Masuda, A., \& Lillis, J. (2006). Acceptance and commitment therapy: Model, processes and outcomes. Behaviour Research and Therapy, 44, 1-25. doi:10.1016/j.brat.2005.06 .006

Ingram, R. E., \& Hollon, S. D. (1986). Cognitive therapy for depression from an information processing perspective. In R. E. Ingram (Ed.), Information processing approaches to clinical psychology (pp. 259281). Orlando, FL: Academic Press.

James, W. (1890). The principles of psychology. New York, NY: Holt. doi:10.1037/11059-000

Jamieson, J. P., Nock, M. K., \& Mendes, W. B. (2012). Mind over matter: Reappraising arousal improves cardiovascular and cognitive responses to stress. Journal of Experimental Psychology: General, 141, 417-422. doi: $10.1037 / \mathrm{a} 0025719$

Jamieson, J. P., Mendes, W. B., Blackstock, E., \& Schmader, T. (2010). Turning the knots in your stomach into bows: Reappraising arousal improves performance on the GRE. Journal of Experimental Social Psychology, 46, 208-212. doi:10.1016/j.jesp.2009.08.015

Kashdan, T. B., \& Roberts, J. E. (2006). Affective outcomes and cognitive processes in superficial and intimate interactions: Roles of social anxiety and curiosity. Journal of Research in Personality, 40, 140-167. doi: 10.1016/j.jrp.2004.10.005

Kassam, K. S., \& Mendes, W. B. (2013). The effects of measuring emotion: Physiological reactions to emotion situations depend on whether someone is asking. PLoS ONE, 8(6), e64959. doi:10.1371/ journal.pone.0064959

Kenny, L. M., \& Bryant, R. A. (2007). Keeping memories at an arm's length: Vantage point of trauma memories. Behaviour Research and Therapy, 45, 1915-1920. doi:10.1016/j.brat.2006.09.004

Kenny, L. M., Bryant, R. A., Silove, D., Creamer, M., O’Donnell, M., \& McFarlane, A. C. (2009). Distant memories: A prospective study of vantage point of trauma memories. Psychological Science, 20, 10491052. doi:10.1111/j.1467-9280.2009.02393.x

Kessler, R. C., Berglund, P., Demler, O., Jin, R., \& Walters, E. E. (2005). Lifetime prevalence and age-of-onset distributions of DSM-IV disorders in the National Comorbidity Survey Replication. Archives of General Psychiatry, 62, 593-602. doi:10.1001/archpsyc.62.6.593

Kessler, R. C., McGonagle, K. A., Zhao, S., Nelson, C. B., Hughes, M., Eshleman, S., . . . Kendler, K. S. (1994). Lifetime and 12-month prevalence of $D S M-I I I-R$ psychiatric disorders in the United States: Results from the National Comorbidity Survey. Archives of General Psychiatry, 51, 8-19. doi:10.1001/archpsyc.1994.03950010008002

Kirschbaum, C., Pirke, K.-M., \& Hellhammer, D. H. (1993). The "Trier Social Stress Test": A tool for investigating psychobiological stress responses in a laboratory setting. Neuropsychobiology, 28, 76-81. doi: $10.1159 / 000119004$

Kober, H., Mende-Siedlecki, P., Kross, E., Mischel, W., Hart, C. L., \& Ochsner, K. N. (2010). Prefrontal-striatal pathway underlies cognitive regulation of craving. Proceedings of the National Academy of Sciences of the USA, 107, 14811-14816. doi:10.1073/pnas.1007779107

Kross, E. (2009). When the self becomes other. Annals of the New York Academy of Sciences, 1167, 35-40. doi:10.1111/j.1749-6632.2009 .04545.x

Kross, E., \& Ayduk, Ö. (2008). Facilitating adaptive emotional analysis: Distinguishing distanced-analysis of depressive experiences from immersed-analysis and distraction. Personality and Social Psychology Bulletin, 34, 924-938. doi:10.1177/0146167208315938

Kross, E., \& Ayduk, Ö. (2009). Boundary conditions and buffering effects: Does depressive symptomology moderate the effectiveness of distancedanalysis for facilitating adaptive self-reflection? Journal of Research in Personality, 43, 923-927. doi:10.1016/j.jrp.2009.04.004

Kross, E., \& Ayduk, Ö. (2011). Making meaning out of negative experiences by self-distancing. Current Directions in Psychological Science, 20, 187-191. doi:10.1177/0963721411408883
Kross, E., Ayduk, Ö., \& Mischel, W. (2005). When asking “why" does not hurt: Distinguishing rumination from reflective processing of negative emotions. Psychological Science, 16, 709-715. doi:10.1111/j.14679280.2005.01600.x

Kross, E., Duckworth, A., Ayduk, Ö., Tsukayama, E., \& Mischel, W. (2011). The effect of self-distancing on adaptive versus maladaptive self-reflection in children. Emotion, 11, 1032-1039. doi:10.1037/ a0021787

Kross, E., Gard, D., Deldin, P., Clifton, J., \& Ayduk, Ö. (2012). "Asking why" from a distance: Its cognitive and emotional consequences for people with major depressive disorder. Journal of Abnormal Psychology, 121, 559-569. doi:10.1037/a0028808

Kuyken, W., \& Moulds, M. L. (2009). Remembering as an observer: How is autobiographical memory retrieval vantage perspective linked to depression? Memory, 17, 624-634. doi:10.1080/09658210902984526

Lazarus, R. S., \& Folkman, S. (1984). Stress, appraisal, and coping. New York, NY: Springer.

Leary, M. R. (1983). A brief version of the Fear of Negative Evaluation Scale. Personality and Social Psychology Bulletin, 9, 371-375. doi: 10.1177/0146167283093007

Libby, L. K., \& Eibach, R. P. (2011). Visual perspective in mental imager: A representational tool that functions in judgment, emotion, and selfinsight. In M. P. Zanna \& J. M. Olson (Eds.), Advances in experimental social psychology (Vol. 44, pp. 185-245). San Diego, CA: Academic Press.

Liberman, N., Trope, Y., \& Stephan, E. (2007). Psychological distance. In E. T. Higgins \& A. W. Kruglanski (Eds.), Social psychology: A handbook of basic principles (pp. 353-381). New York, NY: Guilford Press.

Marschall, D., Sanftner, J., \& Tangney, J. P. (1994). The State Shame and Guilt Scale. Fairfax, VA: George Mason University.

Mcisaac, H. K., \& Eich, E. (2002). Vantage point in episodic memory. Psychonomic Bulletin \& Review, 9, 146-150. doi:10.3758/BF03196271

Meleshko, K. G., \& Alden, L. E. (1993). Anxiety and self-disclosure: Toward a motivational model. Journal of Personality and Social Psychology, 64, 1000-1009. doi:10.1037/0022-3514.64.6.1000

Mellings, T. M. B., \& Alden, L. E. (2000). Cognitive processes in social anxiety: The effects of self-focus, rumination and anticipatory processing. Behaviour Research and Therapy, 38, 243-257. doi:10.1016/ S0005-7967(99)00040-6

Mischel, W., \& Rodriguez, M. (1993). Psychological distance in selfimposed delay of gratification. In R. R. Cocking \& K. A. Renninger (Eds.), The development and meaning of psychological distance (pp. 109-121). Hillsdale, NJ: Erlbaum.

Mischowski, D., Kross, E., \& Bushman, B. (2012). Flies on the wall are less aggressive: The effect of self-distancing on aggressive affect, $\operatorname{cog}$ nition, and behavior. Journal of Experimental Social Psychology, 48, 1187-1191. doi:10.1016/j.jesp.2012.03.012

Nolen-Hoeksema, S., Wisco, B. E., \& Lyubomirsky, S. (2008). Rethinking rumination. Perspectives on Psychological Science, 3, 400-424. doi: 10.1111/j.1745-6924.2008.00088.x

Oppenheimer, D. M., Meyvis, T., \& Davidenko, N. (2009). Instructional manipulation checks: Detecting satisficing to increase statistical power. Journal of Experimental Social Psychology, 45, 867-872. doi:10.1016/ j.jesp.2009.03.009

Park, J., Ayduk, O., O’Donnell, L. O., Chun, J., Gruber, J., Kamali, M., . . Kross, E. (2013). Cognitive and neural processes underlying positive emotion regulation in bipolar I disorder. Manuscript submitted for publication.

Pennebaker, J. W., Booth, R. J., \& Francis, M. E. (2007). Linguistic Inquiry and Word Count [Computer software]. Austin, TX: LIWC Inc

Pennebaker, J. W., \& King, L. A. (1999). Linguistic styles: Language use as an individual difference. Journal of Personality and Social Psychology, 77, 1296-1312. doi:10.1037/0022-3514.77.6.1296 
Pronin, E., \& Ross, L. (2006). Temporal differences in trait self-ascription: When the self is seen as an other. Journal of Personality and Social Psychology, 90, 197-209. doi:10.1037/0022-3514.90.2.197

Rapee, R. M., \& Heimberg, R. G. (1997). A cognitive-behavioral model of anxiety in social phobia. Behaviour Research and Therapy, 35, 741-756. doi:10.1016/S0005-7967(97)00022-3

Ray, R. D., Wilhelm, F. H., \& Gross, J. J. (2008). All in the mind's eye? Anger rumination and reappraisal. Journal of Personality and Social Psychology, 94, 133-145. doi:10.1037/0022-3514.94.1.133

Schultz, L. T., \& Heimberg, R. G. (2008). Attentional focus in social anxiety disorder: Potential for interactive processes. Clinical Psychology Review, 28, 1206-1221. doi:10.1016/j.cpr.2008.04.003

Segal, Z. V., Williams, J. M. G., \& Teasdale, J. D. (2002). Mindfulnessbased cognitive therapy for depression: A new approach to preventing relapse. New York, NY: Guilford Press.

Selcuk, E., Zayas, V., Gunaydin, G., Hazan, C., \& Kross, E. (2012). Mental representations of attachment figures facilitate emotional recovery following upsetting autobiographical memory recall. Journal of Personality and Social Psychology, 103, 362-378. doi:10.1037/a0028125

Sigel, I., \& McGillicuddy-De Lisi, A. V. (2003). Rod Cocking's legacy: The development of psychological distancing. Journal of Applied Developmental Psychology, 24, 697-711. doi:10.1016/j.appdev.2003.09 .004

Smith, E. R. (2000). Research design. In H. T. Reis \& C. M. Judd (Eds.), Handbook of research methods in social and personality psychology (pp. 17-39). New York, NY: Cambridge University Press.

Spencer, S. J., Zanna, M., \& Fong, G. T. (2005). Establishing a causal chain: Why experiments are often more effective than mediational analyses in examining psychological processes. Journal of Personality and Social Psychology, 89, 845-851. doi:10.1037/0022-3514.89.6.845

Spurr, J. M., \& Stopa, L. (2002). Self-focused attention in social phobia and social anxiety. Clinical Psychology Review, 22, 947-975. doi: 10.1016/S0272-7358(02)00107-1

Teasdale, J. D., Moore, R. G., Hayhurst, H., Pope, M., Williams, S., \& Segal, Z. V. (2002). Metacognitive awareness and prevention of relapse in depression: Empirical evidence. Journal of Consulting and Clinical Psychology, 70, 275-287. doi:10.1037/0022-006X.70.2.275

Trope, Y., \& Liberman, N. (2003). Temporal construal. Psychological Review, 110, 403-421. doi:10.1037/0033-295X.110.3.403

Trope, Y., \& Liberman, N. (2010). Construal-level theory of psychological distance. Psychological Review, 117, 440-463. doi:10.1037/a0018963

Turner, S. M., Beidel, D. C., \& Larkin, K. T. (1986). Situational determinants of social anxiety in clinic and nonclinic samples: Physiological and cognitive correlates. Journal of Consulting and Clinical Psychology, 54, 523-527. doi:10.1037/0022-006X.54.4.523

Weinstock, L. S. (1999). Gender differences in the presentation and management of social anxiety disorder. Journal of Clinical Psychiatry, 60, $9-13$.

Wilson, T. D., \& Gilbert, D. T. (2008). Explaining away: A model of affective adaptation. Perspectives on Psychological Science, 3, 370386. doi:10.1111/j.1745-6924.2008.00085.x

Wisco, B. E., \& Nolen-Hoeksema, S. (2011). Effect of visual perspective on memory and interpretation in dysphoria. Behaviour Research and Therapy, 49, 406-412. doi:10.1016/j.brat.2011.03.012

Zayas, V., \& Shoda, Y. (2005). Do automatic reactions elicited by thoughts of romantic partner, mother, and self related to adult romantic attachment? Personality and Social Psychology Bulletin, 31, 1011-1025. doi:10.1177/0146167204274100

Zell, E., Warriner, A. B., \& Albarracin, D. (2012). Splitting of the mind: When the you I talk to is me and needs command. Social Psychological and Personality Science, 3, 549-555. doi:10.1177/1948550611430164

Zoccola, P. M., Dickerson, S. S., \& Zaldivar, F. P. (2008). Rumination and cortisol responses to laboratory stressors. Psychosomatic Medicine, 70, 661-667. doi:10.1097/PSY.0b013e31817bbc77

Received November 17, 2012

Revision received October 1, 2013

Accepted October 21, 2013 